\title{
RESISTIVITY RECOVERY OF NEUTRON-IRRADIATED AND COLD-WORKED THORIUM
}

Jiang-Taur Tang

Ph. D. Thesis Submitted to Iowa State University

Ames Laboratory, ERDA

Iowa State University

Ames, Iowa 50011

\section{Date Transmitted: February 1977}

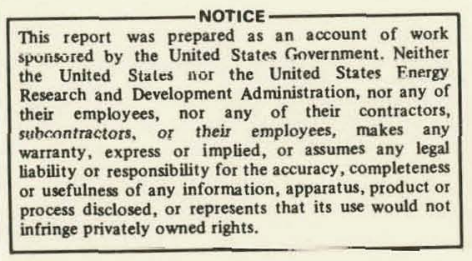

PREPARED FOR THE U.S. ENERGY RESEARCH AND DEVELOPMENT ADMINISTRATION UNDER CONTRACT NO. W-7405-eng-82 


\section{DISCLAIMER}

This report was prepared as an account of work sponsored by an agency of the United States Government. Neither the United States Government nor any agency Thereof, nor any of their employees, makes any warranty, express or implied, or assumes any legal liability or responsibility for the accuracy, completeness, or usefulness of any information, apparatus, product, or process disclosed, or represents that its use would not infringe privately owned rights. Reference herein to any specific commercial product, process, or service by trade name, trademark, manufacturer, or otherwise does not necessarily constitute or imply its endorsement, recommendation, or favoring by the United States Government or any agency thereof. The views and opinions of authors expressed herein do not necessarily state or reflect those of the United States Government or any agency thereof. 


\section{DISCLAIMER}

Portions of this document may be illegible in electronic image products. Images are produced from the best available original document. 
This report was prepared as an account of work sponsored by the United States Government. Neither the United States nor the United States Energy Research and Development Administration, nor any of their employees, nor any of their contractors, subcontractors, or their employees, makes any warranty, express or implied, or assumes any legal liability or responsibility for the accuracy, completeness, or usefulness of any information, apparatus, product or process disclosed, or represents that its use would not infringe privately owned rights.

Available from: National Technical Information Service U. S. Department of Commerce P.O. Box 1553

Springfield, VA 22161

Price: Microfiche $\$ 3.00$ 
TABLE OF CONTENTS

Page

INTRODUCTION

Recovery of Irradiated Face-Centered

Cubic Metals

Recovery of Cold-Worked Face-Centered Cubic Metals

Recovery Studies of Irradiated Thorium

EXPERIMENTAL PROCEDURE

12

Specimen Preparation

Irradiation Experiments

Cold-Work Experiments

Annealing Experiments

Electrical Resistivity Measurement

Isochronal Annealing

Activation Energies $\quad \therefore \quad 25$

Isothermal Annealing and Kinetics. 55

DISCUSSION

Nature and Extent of Radiation Effect on the Resistivity of Thorium at $80^{\circ} \mathrm{K}$

Interpretation of Stage II Recovery above $80^{\circ} \mathrm{K}$

Activation Energy and Interpretation of 


\section{INTRODUCTION}

Irradiation with energetic particles at low temperatures produces predominantly Frenkel defects, that is, interstitials and vacancies in equal numbers. The specific nature of the resulting microscopic radiation damage, however, depends upon a variety of factors, such as the type, energy, and dose of the incident radiation, the material being 1rradiated, and the temperature at which the irradiation occurs. For the same material, various irradiating particles may produce different numbers and arrangements of vacancies and interstitials in the lattice.

When metals are heated following irradiation at cryogenic temperatures, the induced point defects become mobile and may interact with one other and with extrinsic point defects. Some of the more important interactions are: annihilation of vacancies and interstitials by recombination; migration of point defects to dislocations; aggregation and trapping at impurities of point defects. In an isochronal anneal these interactions lead to the so-called recovery, in several stages, of physical properties of the samples. Each of the annealing stages is characterized by a temperature range (called the homologous temperature when expressed as a fraction of the absolute melting point), one or several activation energies of the mobile defects, depending on 
whether or not the stage is subdivided and on the kinetics of Interaction:

Corbett (1) and Damask and Dienes (2) have discussed several techniques for monitoring the radiation damage and for detecting various stages of the annealing process. The majority of the annealing studies conducted so far have employed electrical resistivity as a measure for the change in the defect concentration. As is well-known, the total resistivity of a metal is resolved into a residual component $\left(\rho_{0}\right)$, which 1 s independent of temperature, and another component, which is temperature dependent and associated with phonon-1nduced scattering of electrons. For low defect concentrations, Matthiessen's rule states that the increase in resistivity of a metal due to a small concentration of solute atoms or defects is in general independent of the temperature. Thus when the defect concentrations are sufficiently small, the increase in residual resistivity is expected to be linearly proportional to the defect or Impurity concentration, since nonlinear interference effects among defects can be neglected (3).

\author{
Recovery of Irradiated \\ Face-Centered Cubic Metals
}

The earliest study of postirradiation recovery by electrical resistivity measurement was conducted on face-centered 
cub1c ( $f c c$ ) metals, notably high-purity copper. The annealing spectrum is generaliy divided into five major stages (4).

Stage I was first recorded in $\mathrm{Cu}$ below $60^{\circ} \mathrm{K}$ in isochronal annealing by Cooper et al.'(5). Many reports (6-9) have since appeared in the literature on this stage. A characteristic of stage I is the subdivision into five substages. Corbett et al. $(8,9)$ attributed the substages $I_{A}, I_{B}$, and $I_{C}$ to the recombination of close Frenkel pairs, $I_{D}$ to recombination of interstitials with their own vacancies in a small number of Jumps (correlated recombination), and $I_{E}$ to.irecombination involving other vacancies in a large number of jumps (uncorrelated recombination). Recent studies (10,11) using fleld-ion microscopy (FIM) have substantiated the annealing mechanism of stage I, which involves migration of free interstitials.

Stage II occurs in the temperature range between the termination of free interstitial migration in stage $I$ and the beginning of migration of a second type of defects in stage III. The onset of this stage depends sensitively on the purity of the sample, the Irradiation dose, and the type of bombarding particles: Experimental results (12-19) obtalned from dilute alloys of $\mathrm{Al}$ or $\mathrm{Cu}$ indicate that the presence of impurity atoms gives rise to subdivision of stage II as in stage I. Despite these results, stage II has not been systematically studied because of the rather complex 
behavior of the irradiation-induced defects and the sensitive dependence on impurities: Thus the recovery processes responsible for stage II are not well understood. The concelvable interpretation of stage II recovery is based on the detrapping of interstitials from impurity atoms or on the rearrangement or coagulation of the interstitial clusters formed in stage I $(12,13,21,22)$.

Stage III recovery occurs in $\mathrm{Cu}, \mathrm{Ag}, \mathrm{NI}, \mathrm{Al}$, and $\mathrm{Pt}$ at about 0.2 to $0.25 \mathrm{Tm}$. After electron Irradiation, recovery in this stage shows a dose dependence in $A I(16,23)$, Cu (24), Au $(25,26)$, and Pt (27). In all these metals a single well defined peak has been observed in stage III, which is, however, shifted to lower temperatures with increasing irradiation dose. A subdivision of stage III has been observed in AI irradiated by fast neutrons. Substages have also been observed in $\mathrm{Cu}, \mathrm{Au}$, and $\mathrm{Ag}$ at low neutron doses $(22,28)$. An increase in dose tends. to shift the high temperature peaks to lower temperatures until the subpeaks converge.

The origin of stage III has been a subject of controversy for some time.' Both vacancy and split-interstitial migrations have been propnsed (2l) for fcc metals. For bcc metals an extrinsic process, which involves the migration of interstitial impurity atoms, has been proposed in addition to the intrinsic process. Considerable evidence has been accumulated to support the migration of interstitial impurity 
atoms in group VA metals ( $\mathrm{V}, \mathrm{Nb}$, and $\mathrm{Ta}$ ) and $\alpha-\mathrm{Fe}(29,30,31$, 32). For the identification of stage III mechanisms, a reliable determination of activation energy for migration of the involved defects is of extreme importance.

The influence of such impurity atoms as $\mathrm{Mg}, \mathrm{Zn}, \mathrm{Cu}, \mathrm{Ag}$, and $\mathrm{Sn}$ on stage III recovery in neutron and electron irradiated Al has been studied most extensively by Dimitrov-Frois. et al. (33-37), Peters and Shearin (16), and Sosin et al. (17, 38). The activation energies deduced for the dizute alloys of Al seem to be the same as that observed in pure Al. For fcc metals other than Al, little information is available about the influence of impurities on stage III recovery.

Recovery of Cold-Worked

Face-Centered Cubic Metals

Plastic deformation is expected to produce dislocations and point defects of both vacancy and interstitial type. The recovery stages of deformed metals are related largely to the annealing of point defects (39). The recovery of cold-worked fcc metals has been reviewed by Balluffi et al. (40) and van den Beukel (4I). Isochronal recovery on AI, Au, Pt, N1, $\mathrm{Ag}$, and $\mathrm{Cu}$ after heavy plastic deformation at $78^{\circ} \mathrm{K}$ (at $20^{\circ} \mathrm{K}$ for Al) features two main stages (II and III, or III and IV. for Pt for no good reason) $(42-46)$.

Stage II recovery has not been investigated as extensively as stage III. In $\mathrm{Cu}, \mathrm{N1}$, and $\mathrm{Ag}$, stage II shows 
substages and shoulders, whereas in $A l, A u$, and Pt it features well-defined peaks. It was shown by Buck (47) that stage II recovery in heavily cold worked $\mathrm{Cu}$ single crystals Is about the same in 99.98 and $99.999 \%$ pure samples, indicating that stage II is probably intrinsic rather than extrinsic. Stage II recovery has been interpreted by several workers (48-53). While van den Beukel (4I) explained stage II in terms of migration or break up of interstitial agglomerates, Corbett (48) suggested that stage II recovery is due to the release of interstitials previously trapped by impurities.

All cold worked fcc metals show pronounced stage III recovery. In some metals such as $\mathrm{Cu}, \mathrm{Ni}$, and $\mathrm{Al}$, stage III Involves several substages, whereas in others ( $A u$ and $P t$ ), no substages are observed. The relationship between the fine structure of stage III and the degree of deformation is not clearly known.

It is difficult to devise critical experiments to identify the point defects involved in stages II and III in cold-worked metals. The interpretation of the recovery spectrum of cold-worked metals requires pertinent data obtained from other studies, such as equilibrium, quenching, and Irradiation experiments. With the possible exception of $\mathrm{Ag}, \mathrm{NI}$, and $\mathrm{Au}$, the activation energies deduced for the Irradiated fcc metals such as $\mathrm{Pt}, \mathrm{AI}$, and $\mathrm{Cu}$ agree reasonably 
well with those deduced from deformation experiments (41). Stage III of irradiated or cold-worked Pt and AI is commonly attributed to the migration of single vacancies $(16,38,42$, 54). For Ag; $\mathrm{Ni}$, and $\mathrm{Au}$ there is some doubt as to whether stage III involves the same process for cold-worked and irradiated samples because of the somewhat higher activation energies deduced for the irradiated samples. Seeger et al. $(55,56)$ have thus proposed that for the case of irradiation, stage I is due to the migration of free interstitials of the <110> crowdion form and stage III involves the migration of interstitials of the $\langle 100\rangle$ split or dumbbell configuration. Data for stage III recovery of cold-worked fcc metals seem to support either the single vacancy or a di-vacancy migration model ( $41,57-59)$.

Recovery Studies of Irradiated Thorium

Considerable interest has been generated in Th by virtue of the potential application of the metal as a breeder of the fissionable ${ }^{23} \mathrm{U}$ via chain reactions. However, resistivity recovery study of low temperature $\left(80^{\circ} \mathrm{K}\right.$ or below) deformed Th is still not available and there have been only three studies in which resistivities of irradiated thorium have been measured. Brinkman and Gilbert (60) observed a saturation effect in the resistivity of Th after bombardment by $9 \mathrm{MeV}$ protons. Subsequent irradiation with 


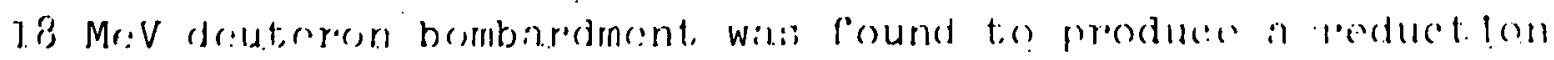
In the saturation villue of the resilativily.

Bowman et al. (6I) measured the electrical resistivity of a $0.17 \mathrm{~mm}$ Th foil at $-146^{\circ} \mathrm{C}$ after irradiation by $19 \mathrm{MeV}$ deuterons at $-70^{\circ} \mathrm{C}$ for various periods and annealing at temperatures up to $100^{\circ} \mathrm{C}$. The resistivity showed a saturation effect analogous to that observed by Brinkman and Gilbert. Exposure of Th to $38 \mathrm{MeV}$ alpha particles also caused a saturation effect, which was incomplete, however, due to insufficient irradiation. Isochronal anneal for one hour at $200-300^{\circ} \mathrm{C}$ was shown to bring about a complete recovery of the damage.

More recently, Schmidt (62) introduced radiation damage in $99.9 \%$ pure Th by homogeneously doping the metal with a short-lived isotope $\left({ }^{2}{ }^{8} \mathrm{Th}\right)$ at $4.2^{\circ} \mathrm{K}$. Subsequently an isochronal anneal was conducted between 4.2 and $1150^{\circ} \mathrm{K}$. This annealing range covers stage I through IV as shown in Figure 1.. The various stages occurred approximately at $4.2-48^{\circ} \mathrm{K}$ for stage I, $48-230^{\circ} \mathrm{K}$ for stage II, $230-400^{\circ} \mathrm{K}$ for stage III, and $400-1100^{\circ} \mathrm{K}$ for stage IV. Stage I was studied in greater detail than other stages. Five substages were found in stage I in analogy to $\mathrm{Cu}$ except that the substage peaks were not so well-defined in Th. Activation energies determined for the stages below $80^{\circ} \mathrm{K}$ were: $I_{B}-0.021 \pm$ $0.002 \mathrm{eV}, I_{D}-0.0875 \pm 0.002 \mathrm{eV}, I_{E}-0.0869 \pm 0.002 \mathrm{eV}$, $I I_{A}-0.100 \pm 0.01 \mathrm{eV}$ and $I I_{B}-0.182 \pm 0.01 \mathrm{eV}$. 


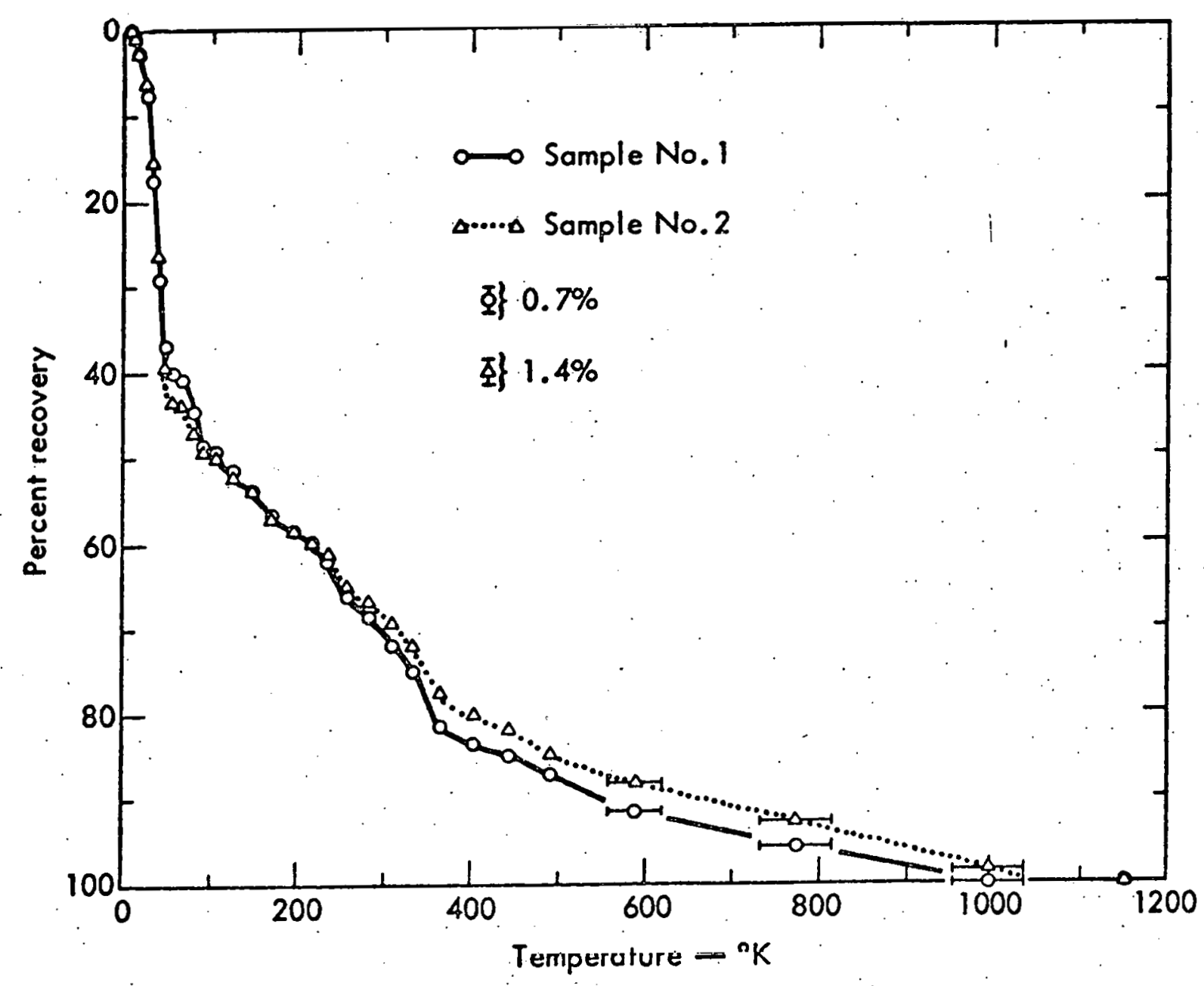

Figure 1. Isochronal recovery curve for thorium damaged by internal alpha decay at $4.2^{\circ} \mathrm{K}$. Resistivity measured at $4.2^{\circ} \mathrm{K}$ following $15-\mathrm{min}$. anneals at the temperatures indicated (69). 
Several reports have revealed pronounced influences of carbon on the mechanical properties of Th (63, 64), notably (1) the emergence of a yield point whose magnitude increases with the C content; (2) a strain-rate sensitivity; (3) a ductile-brittle transition temperature when the $C$ content exceeds 500 wt ppm; (4) impurity strengthening; and (5) a relatively strong temperature dependence of the flow stress. All these effects are normaliy associated with bcc metals and very atypical of the fcc metals. Zerwekh and Scott (65) and Peterson et al. $(63,64)$ have thus concluded that the carbon atoms in thorium must interact strongly with. dislocations, thereby controlling the deformation behavior below room temperature according to Friedel's random solute barrier mechanism (66). The reason for the unusually strong interactions of $\mathrm{C}$ atoms with dislocations in $\mathrm{Th}$ is not known, however.

As mentioned previously, there are two possible interpretations for the stage III recovery of fcc metals -the migration of vacancies and the migration of interstitials of the <l00> dumbbell form. In bcc metals such as $\alpha-F e$, $\mathrm{V}, \mathrm{Nb}$, and $\mathrm{Ta}$, stage III is explained in terms of interstitial impurities migration. The unusual mechanical behavior of Th metal containing $C$ described has generated. considerable interest in regard to the effect of $C$ on the recovery behavior of Th deformed or irradiated at cryogenic 
temperatures. The present study was initiated with the hope that a better understanding could be attained of the annealing processes in stages II and III and of the role played by $C$ atoms in these processes.

Electrical resistivity measurements were chosen as the means to measure the change in defect concentration. This approach has the advantage of high sensitivity and accuracy and is easy to perform. Although it is difficult to specify the type of defects responsible for resistivity change, valuable information has been gained from the measurements concerning the dependence of the resistivity recovery on the initial defect density, which, in turn, varies with the fluence of fast neutrons or with the degree of deformation and with impurities. 


\section{EXPERIMENTAL PROCEDURE}

\section{Specimen Preparation}

Pure thorium and thorium-carbon alloys were prepared by electron-beam melting. The starting materials were arcmelted into fingers (67) and drawn into wire. An intermediate annealing was performed before the wires reached their final dlameter of about $0.70 \mathrm{~mm}$ with a length of about 40. $\mathrm{mm}$. The final anneal was done in vacuum (residual pressure $\sim 2 \times 10^{-7}$ torr) at $800^{\circ} \mathrm{C}$ for four hours. Before and after each anneal, specinens were thoroughly cleaned in a mixture of one part water, one part concentrated nitric acid and a small amount of sodium silicofiuoride $\left(\mathrm{Na}_{2} \mathrm{SiF}_{6}\right)$. All specimens were stored in an evacuated desiccator to avoid oxidation.

For an accurate determination of the state of purity of the final annealed and cleaned specimens, a complete chemical analysis was performed involving various techniques. Notably the wet process for carbon spectrography for metallic impurities, and vacuum fusion for gaseous (oxygen, nitrogen, and hydrogen) impurities. The results of the chemical analysis are shown in Table 1 .

\section{Irradiation Experiments}

Neutron irradiation experiments were conducted in a cryostat Installed in the V-2 thimble of the Amcs Laboratory 
Table 1: Analysis of annealed thorium specimens in ppm by weight

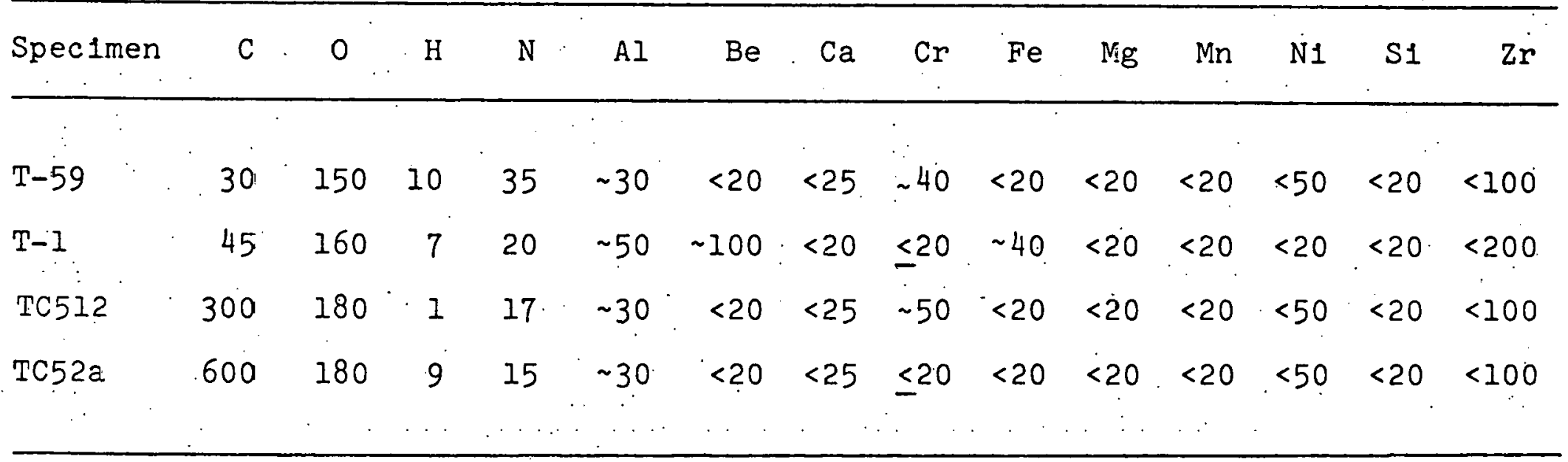


Research Reactor. The cryostat was installed inside a flux converter which had a cadmium shield of $0.78 \mathrm{~mm}$ thickness. The fast neutron flux was about $1.5 \times 10^{12} \mathrm{n} / \mathrm{cm}^{2}-\mathrm{sec}$ $(E>0.1 \mathrm{MeV})$. The specimens were immersed in liquid nitrogen and temperature was recorded by two copperconstantan thermocouples attached to the specimen tube. Irradiation was conducted with fluences at $1.3 \times 10^{18} \mathrm{n} / \mathrm{cm}^{2}$ $(E>0.1 \mathrm{MeV})$. After irradiation, the specimens were transferred to a liquid nitrogen dewar for storage and for decay of induced radioactivity. Care was exercised to avoid a temperature rise during the transfers from the Reactor to the storage dewar and from the dewar to the specimen holder.

\section{Cold-Work Experiments}

Samples were deformed by compression in liquid nitrogen by amounts ranging from about 5 to $40 \%$. The apparatus used for low-temperature compression was similar to that described by Dimitrov and Dimitrov-Fois (68). The wire was compressed between the plane surfaces of two heat-treated steel disks, Immersed in liquid nitrogen. The deformed specimens were mounted on the specimen holder, which had been constructed for resistivity measurements at $80^{\circ} \mathrm{K}$ and annealing.

For square wires of side $e_{0}$, the amount of deformation corresponding to a final thickness. e would be $\bar{\varepsilon}=\ln e_{0} / \mathrm{e}$. 
However, this formula cannot be used for wire which has inftially a circular cross-section. The following relationship was established (68):

$$
\bar{\varepsilon}=\ln \frac{e_{0}}{e}-\frac{1}{2}\left[1-\left(\frac{e}{e_{0}}\right)^{2}\right]
$$

by assuming that the cross-section of the compressed wire can be approximated by a rectangle plus two half-circles.

\section{Annealing Experiments}

Both isochronal and 1sothermal annealing of irradiated or deformed specimens from 120 to $400 \% \mathrm{~K}$ were carried out in a constant temperature bath, using three different baths:

(1) Freon 12 precooled by l1quid nitrogen for 120 to $200^{\circ} \mathrm{K}$;

(2) absolute ethyl alcohol precooled by liquid nitrogen and Freon 12 and heated by a resistance winding with a Bayley. precision temperature controller for 220 to $320^{\circ} \mathrm{K}$; and (3) Dow Corning 550 fluid with the same heater and temperature controller for higher temperatures. The temperature of the annealing bath can be controlled and maintained to within $\pm 0.5^{\circ} \mathrm{K}$.

Electrical Resistivity Measurement

Electrical resistivity was measured by the standard four-probe dc potentiometric technique. A Rubicon (model 2768) six-dial potentiometer was used, which has a sensitivity of $\pm 0.01 \mu \mathrm{v}$. To support the high precision 
emf measurements by the Rubicon potentiometer, the input current ( $20: 5$ A) was stabilized by a North-H1lls precision. constant current source, which control the current within $\pm 1 \mu \mathrm{A}$. The current source was calibrated with respect to a Leeds-Northrup standard resistor. A normal-and-reverse procedure is used to compensate the effect caused by. spurious thermal emfs in the clrcuit. The measurements were made on specimens immersed in liquid nitrogen at one atmosphere pressure. Absolute resistivity values were. estimated to be accurate to $\pm 1 \%$, primarily from errors in measuring the specimen cross-section and the length between the potential leads. Relative errors were less than $\pm 0.0001 \mu \Omega-\mathrm{cm}$, however. 


\section{RESULTS}

\section{Isochronal Annealing}

The recovery of the neutron irradiation-induced resistivity for the specimens irradiated to $1.3 \times 10^{18} \mathrm{n} / \mathrm{cm}^{2}$ $(E>0.1 \mathrm{MeV})$ is shown in Figure 2 . Here the percentages of recovery are plotted against the temperatures at which the specimens underwent 15-minute anneals. The differential curves which show the peaks in different stages are also shown in the same figure. For better precision, two specimens of each composition were examined. The annealing was conducted from $120^{\circ} \mathrm{K}$ up to $420^{\circ} \mathrm{K}$, and two stages can be. seen from the recovery spectra. Following Schmidt's (62) designation, the main recovery stage is named stage III, which covers the temperature range from about 240 to $400^{\circ} \mathrm{K}$ for both pure Th and Th-C alloys. The excess resistivities induced by irradiation are designated as $\Delta \rho_{0}$ which is seen to be larger in the Th-C alloy. However, the percentage of recovery at the end of stage III is higher in pure Th. The differential recovery spectra show the main peak position at about $320^{\circ} \mathrm{K}(0.16 \mathrm{Tm})$ for both pure $\mathrm{Th}$ and the $\mathrm{Th}-0.03 \mathrm{w} / \mathrm{o}$ $C$ alloy. It will be shown that the addition of carbon atoms to thorium seems to enhance stage II recovery and to suppress stage. III recovery.

Figure 3 shows the recovery of resistivity in three specimens of pure Th induced by cold-work of different 
Figure 2. Isochronal recovery and differential recovery curves for pure $T h(T-59)$ and $T h-0.03 \mathrm{w} / \mathrm{O} C$ alloy (TC512) irradiated at $80^{\circ} \mathrm{K}$. Resistivity measured at $80^{\circ} \mathrm{K}$ following $15-\mathrm{min}$. anneals at the temperatures indicated $\left(10^{\circ} \mathrm{K}\right.$ interval). $\rho_{I}$ is the as-irradiated resistivity, $\rho_{u}$ the residual resistivity, and $\Delta \rho_{0}=\rho_{I}-\rho_{u}$ is the resistivity increase by irradiation. 


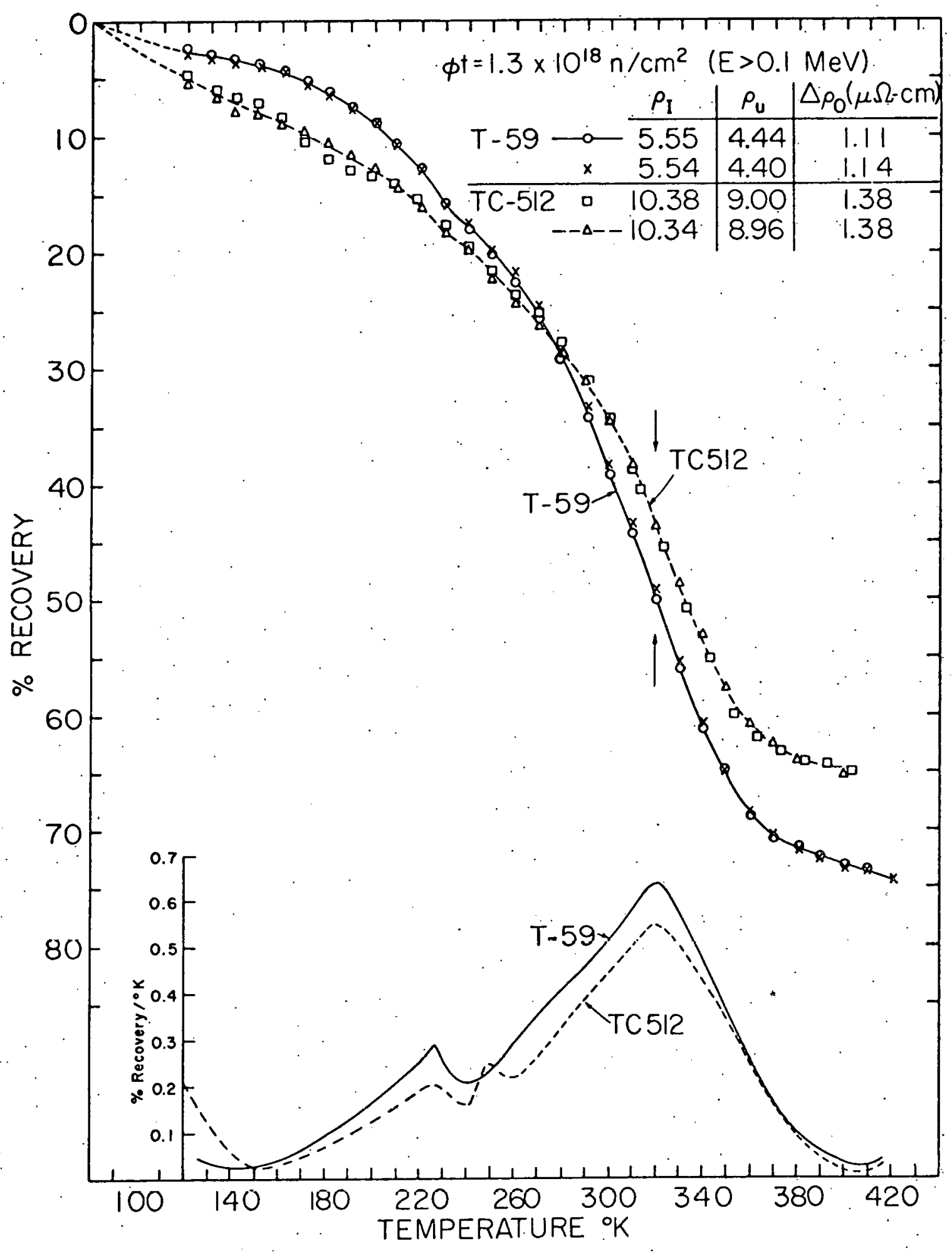




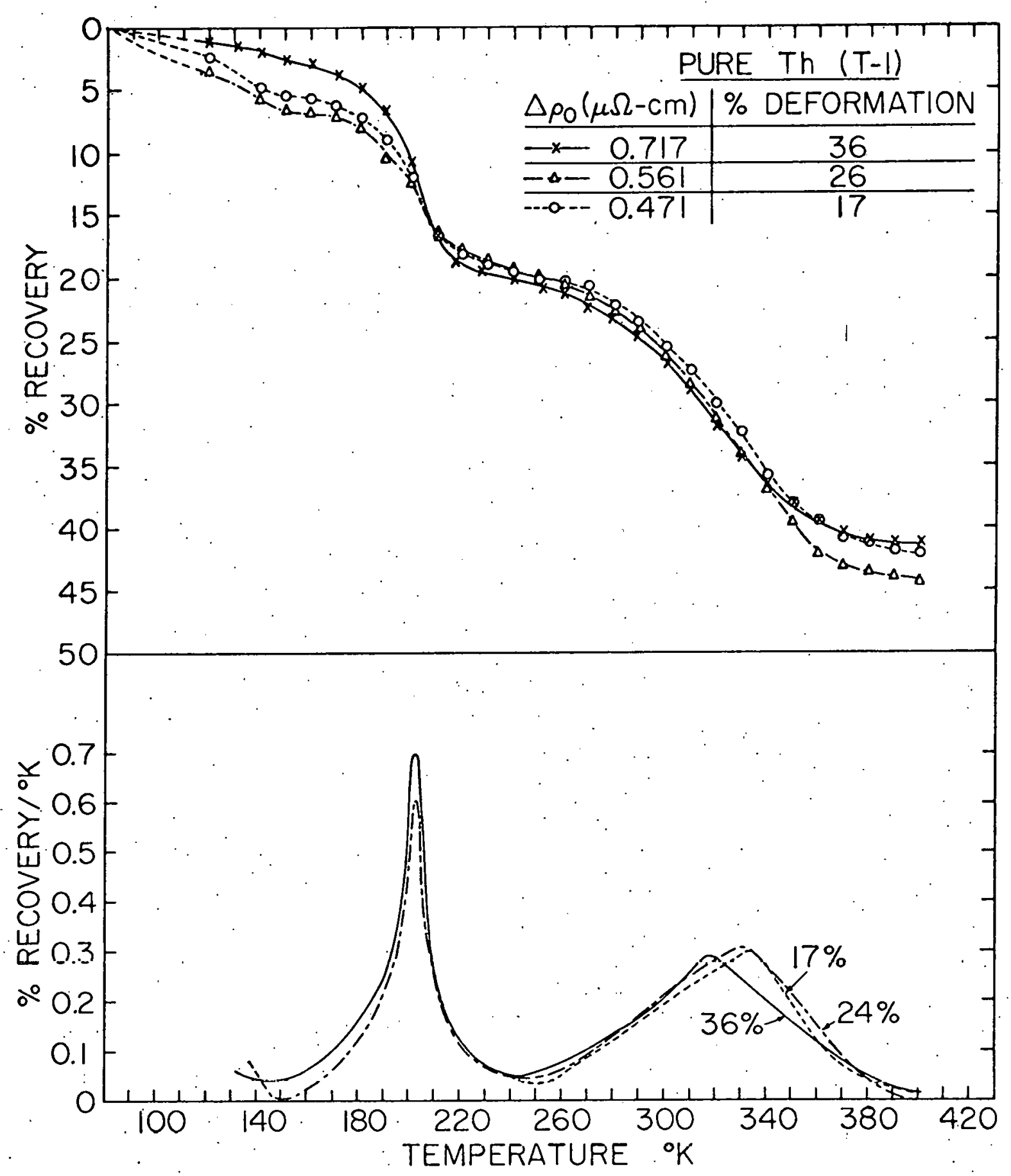

Figure 3. Isochronal recovery and differential recovery curves for pure $\mathrm{Th}$ deformed at $80^{\circ} \mathrm{K}$. Resistivity measured at $80^{\circ} \mathrm{K}$ following $15-\mathrm{min}$. anneals at the temperatures indicated $\left(10^{\circ} \mathrm{K}\right.$ interval). $\Delta \rho_{0}$ is the resistivity increase by deformation. 
amounts at $80^{\circ} \mathrm{K}$. The recovery spectra are seen to be clearly divided in two main parts in all cases. The two main recovery ranges are conventionally called stage II and III (4I). The temperature ranges for stages II and III recovery peaks are about from $150^{\circ}$ to $240^{\circ} \mathrm{K}$ and $240^{\circ}$ to $400^{\circ} \mathrm{K}$, respectively. These ranges are seen to be independent of the amount of deformation. Stage III temperature range corresponds to the main recovery stage in the irradiated specimens described previously. Figure 3 shows a shift of the peak temperatures of stage III for pure Th from 333 to $318^{\circ} \mathrm{K}$ with deformation Increasing from $17 \%$ to $36 \%$. This trend is also observed in the Th-C alloys in Figures 4 and 5. Aiso, in the latter figures a slight tncrease of stage III peak intensity with Increasing deformation is observed; whereas in Figure 3 for pure Th an increase in deformation does not seem to change the stage III peak intensity. The peak position for stage II. is seen to be independent of deformation. from Figures 3-5, while the peak intensity for stage II slightly increases with increasing deformation for both pure Th and the Th-C alloys.

The addition of carbon to Th causes a small shift of the stage II peak position. As shown in Figure 6, for instance, the peak temperature of stage. II 1s lowered from $203^{\circ} \mathrm{K}$ to $196^{\circ} \mathrm{K}$ as a result of adding $0.06 \mathrm{w} / \mathrm{O} \mathrm{C}$ to $\mathrm{Th}$. The most noticeable effect on the recovery spectrum of adding carbon atoms to $T h$ is, however, the suppression of peak height at 


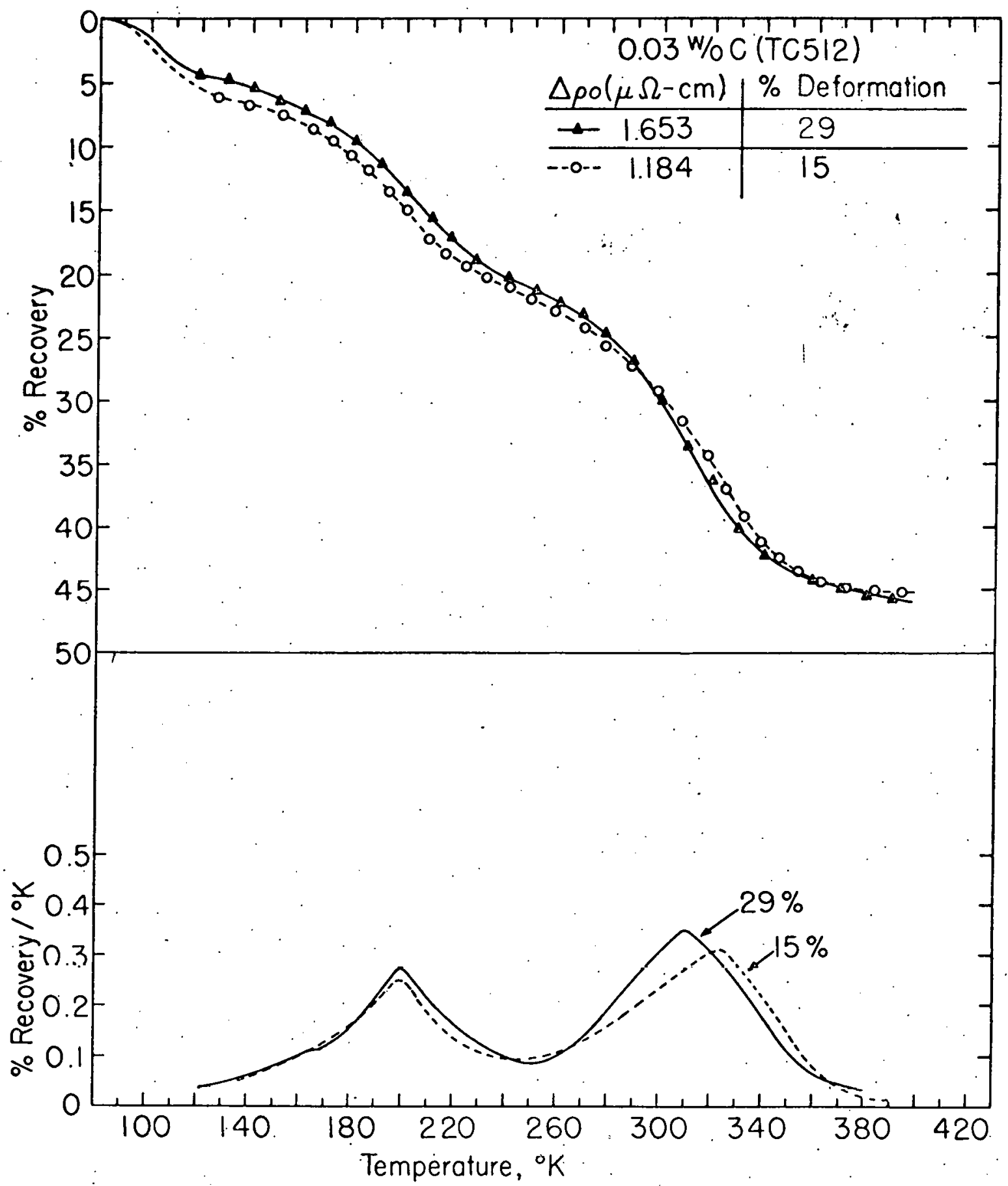

Figure 4. Isochronal recovery and differential recovery curves for Th-0.03 w/O C alloy deformed at $80^{\circ} \mathrm{K}$. Resistivity measured at $80^{\circ} \mathrm{K}$ following $15-\mathrm{min}$. anneals at the temperatures indicated $\left(10^{\circ} \mathrm{K}\right.$. interval). $\Delta \rho_{0}$ is the resistivity increase by deformation. 


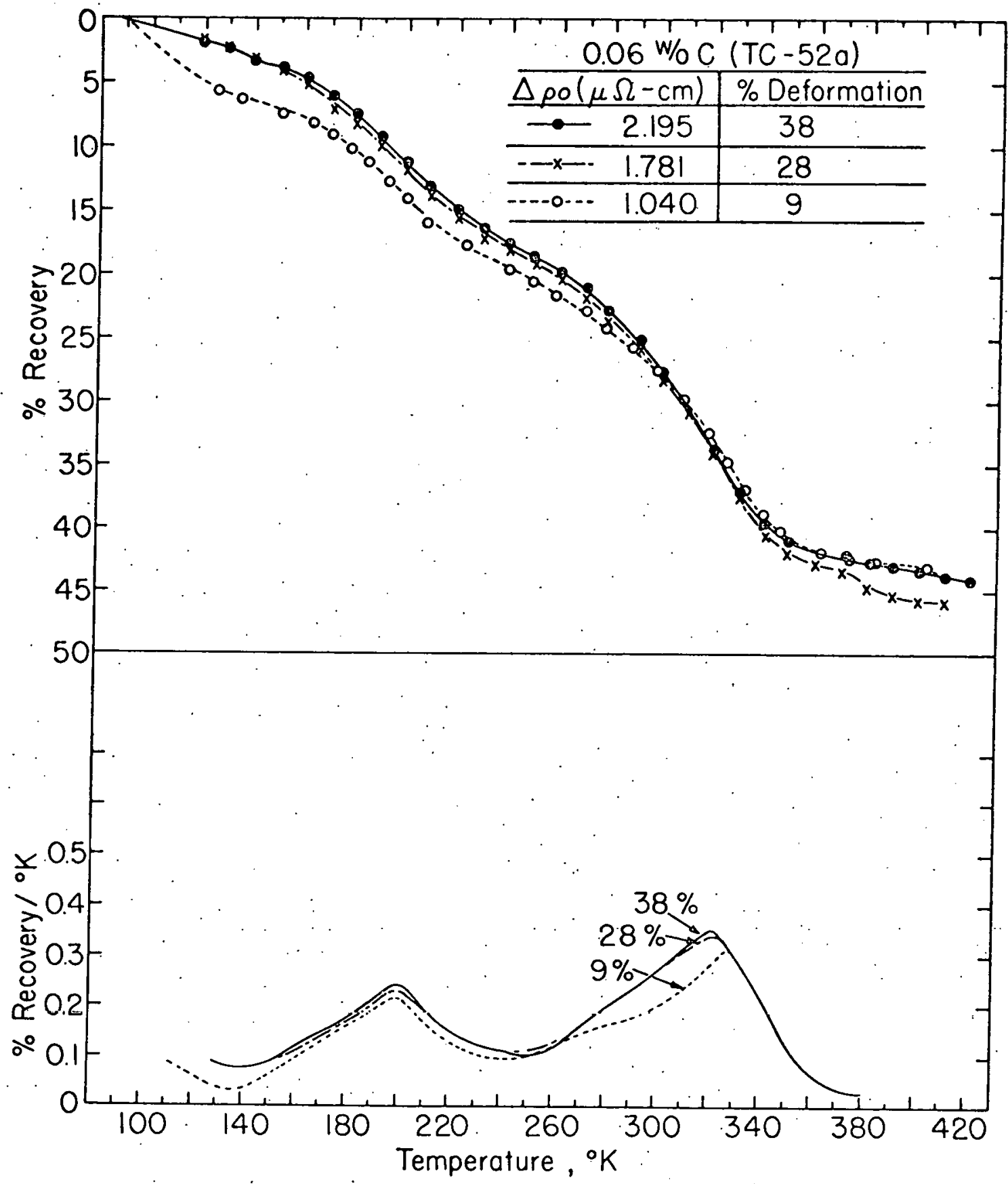

Figure 5. Isochronal recovery and differential recovery curves for $\mathrm{Th}-0.06^{\mathrm{w}} \mathrm{w} / \mathrm{O} \mathrm{C}$ alloy deformed at $80^{\circ} \mathrm{K}$. Resistivity measured at $80^{\circ} \mathrm{K}$ following $15-\mathrm{min}$. anneals at the temperatures indicated $\left(10^{\circ} \mathrm{K}\right.$ interval): $\Delta \rho_{0}$ is the resistivity increase by deformation. 


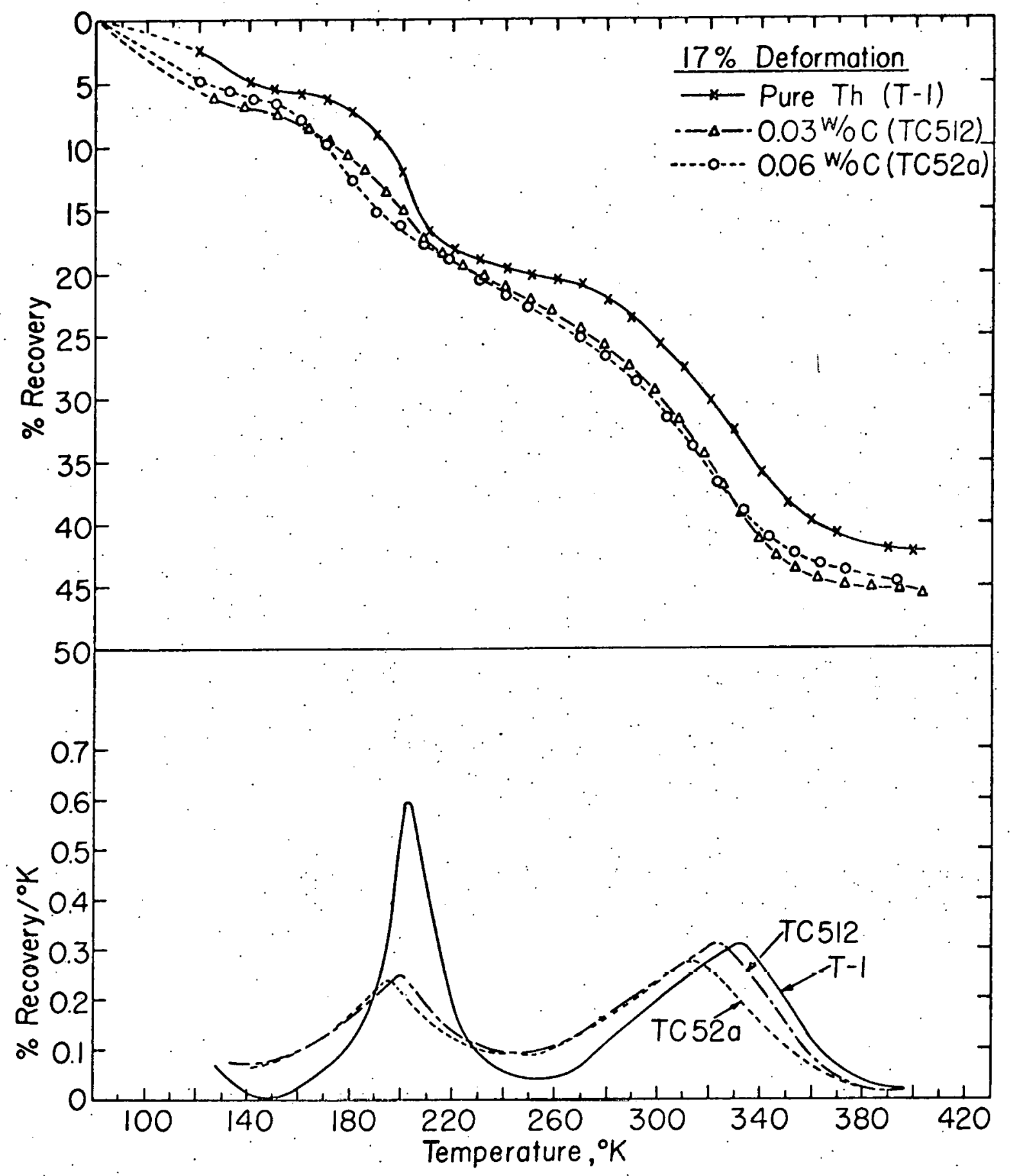

F1gure 6. Dependence of 1sochronal recovery and differential recovery curves on carbon content for Th deformed to $17 \%$ at $80^{\circ} \mathrm{K}$. Resistivity measured at $80^{\circ} \mathrm{K}$ following $15-$ min. anneals at the temperatures indicated $\left(10^{\circ} \mathrm{K}\right.$ interval). 
$\sim 200^{\circ} \mathrm{K}$, although the total percentage of recovery in stage II is almost unchanged. Figure 6 shows that the recovery curves become more flatter and smooth with increasing carbon content. The temperature range for stage III is observed to be from 250 to $400^{\circ} \mathrm{K}$ which has very little effect due to elther increase of deformation or carbon content. Finally, Figure 6 reveals that the influence of carbon on the peak intensity of stage III recovery is negligibly small, although the peak temperature lowered from $333^{\circ} \mathrm{K}$ to $313^{\circ} \mathrm{K}$ as a result of adding $0.06 \mathrm{w} / \mathrm{O} \mathrm{C}$ to thorium.

\section{Activation Energies}

The activation energy, $E$, for a recovery stage or substage is determined by a comparison of the recovery rates, $\mathrm{d} \Delta \mathrm{p} / \mathrm{dt}$, measured at different temperature, $\mathrm{T}$, for identical values of a temperature-independent function, $G$, based on the equation (22):

$$
-\frac{d(\Delta \rho)}{d t}=G(\Delta \rho,\{0\}) K_{0} \exp (-E / k T)
$$

where $\Delta \rho$ is the measured resistivity change, $K_{0}$, a constant, and $k$ the Boltzmann constant. The factor $G$ has ldentical values at different temperatures only if $\Delta \rho$ and the initial damage state symbolized by $\{0\}$ are identical. From this requirement, $E$ is deduced by measuring the change of annealing. temperature from $T_{1}$ to $T_{2}$. The activation energy is thus 
given by

$$
E=\frac{k T_{1} T_{2}}{T_{2}-T_{1}} \ln \left[\left(\frac{d \Delta \rho}{d t}\right)_{T=T_{2}} /\left(\frac{d \Delta \rho}{d t}\right)_{T=T_{1}}\right]
$$

where $\left(\frac{d \Delta \rho}{d t}\right)_{T}$ is the slope of the 1sothermal curve at temperature $T$, which can be evaluated in the $\Delta \rho$ or $\rho$ versus $t$ plot. In practice, $1 t$ is somewhat difficult to construct an accurate slope, and therefore more than one experiment is usually performed. This so-called "ratio-of-slope method" has the Important advantage that the requirement of Identical defect configurations at the two temperatures studied is fulfilied automaticaliy. The results of applying the ratioof-slope method to the recovery data for irradiated specimens are shown in Figures 7 and 8 for the Th-0.03 w/O C alloy. The average activation energies obtalned for stages II and III recovery in the Th-C alloy are 0.55 and $1.07 \mathrm{eV}$, respectively. For Irradiated pure Th the average activation energy for stage III recovery was also determined by the ratio-of-slope method, which yields $E_{I I I} \approx 1.14 \mathrm{eV}$. No value has been obtained in the stage II range.

The activation energies of stage. II and stage III recovery in cold-worked specimens have been determined exclusively by use of the ratio-of-slope method. Typical examples for determining the activation energy. In stage II for deformed $T h$, Th-0.03 w/O C, and Ih-0.06 w/o C alloys are shown in Flgures 9,10 , and 12 , respectively. The deduced 


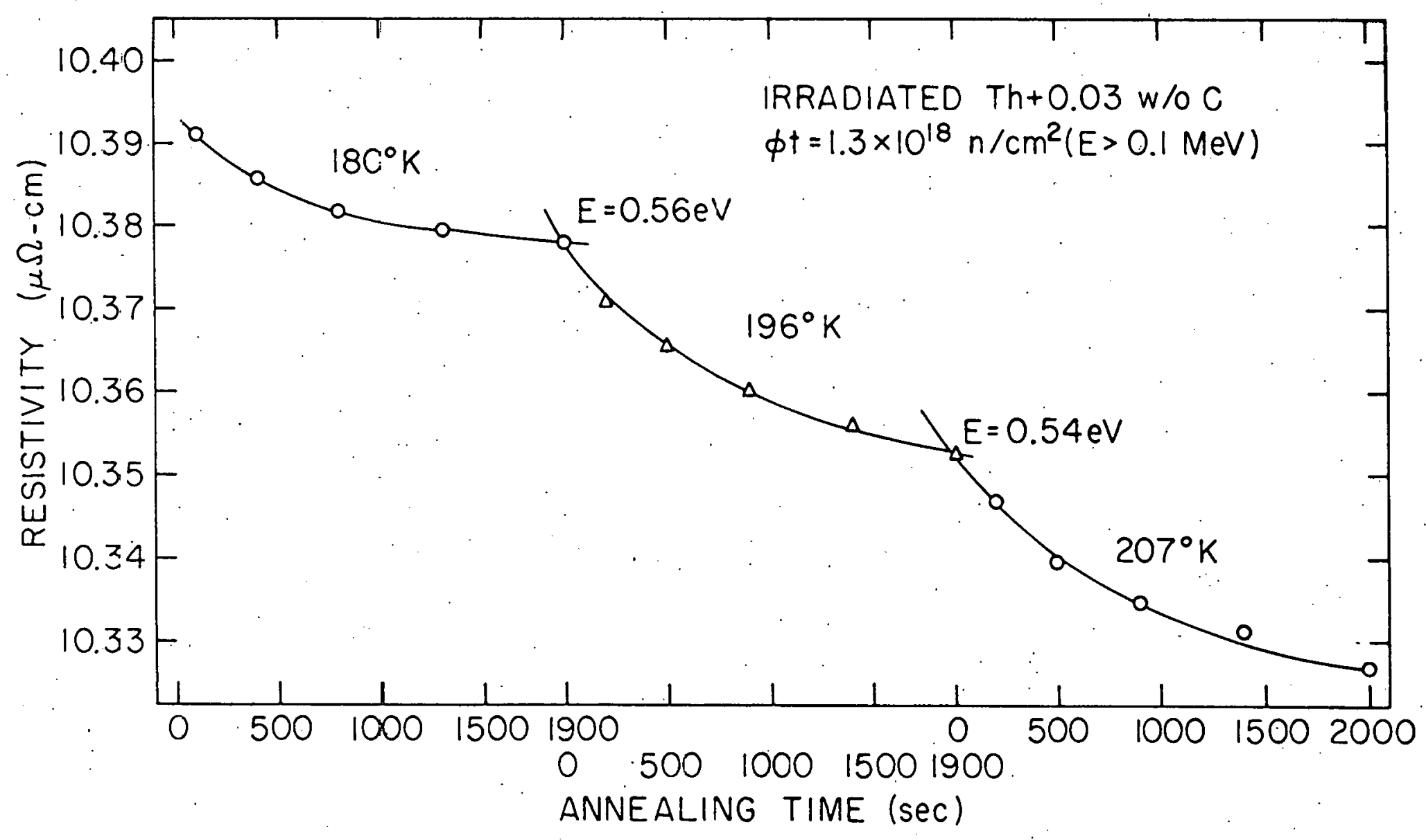

Figure 7. Determination of activation energy of stage II by-the ratio-or-slope method for Th-C alloy irradiated at $80^{\circ} \mathrm{K}$. Resistivity measured at $B 0^{\circ} \mathrm{K}$. 


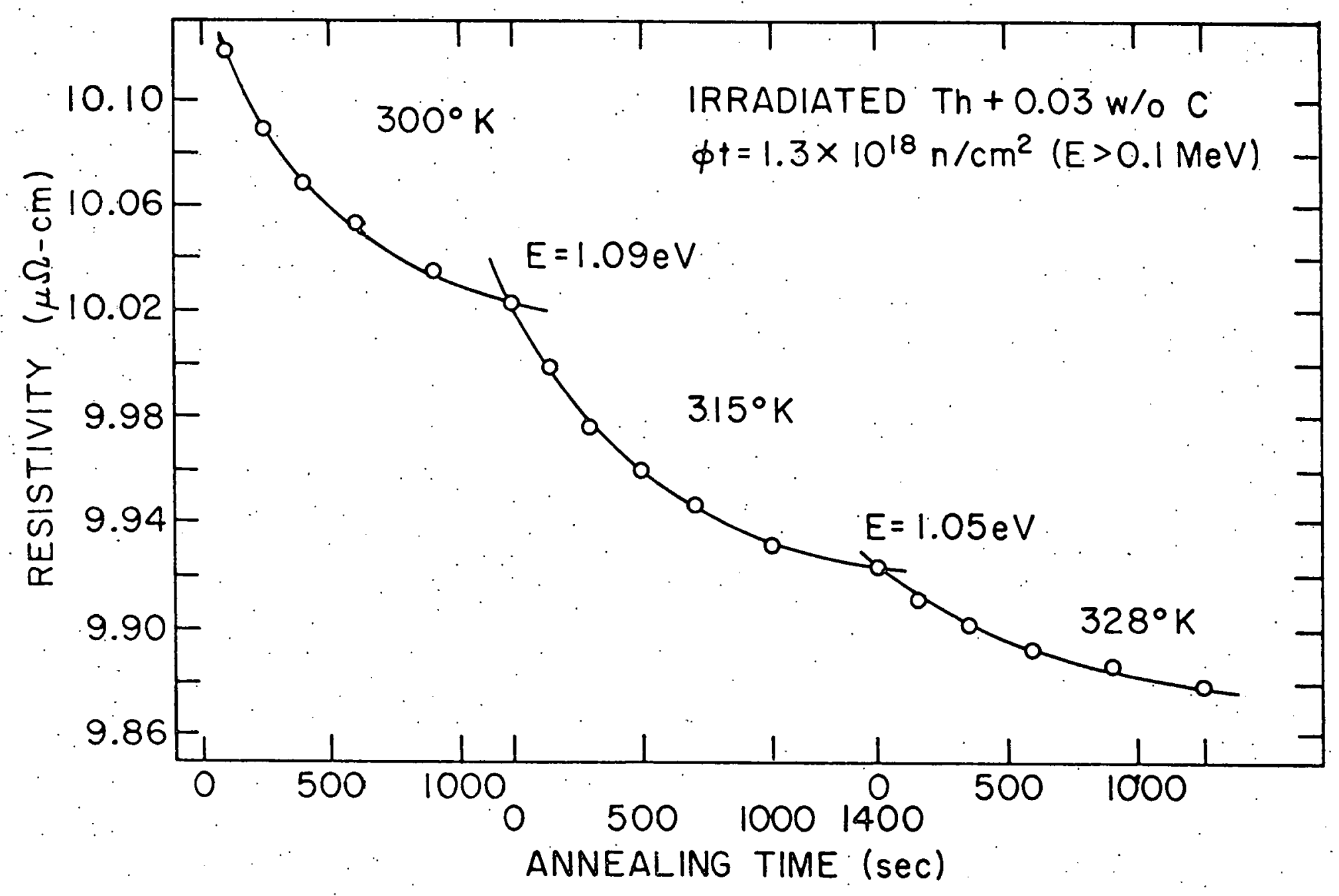

Figure $\varepsilon$. Determination of activation energy of stage III recovery by the ratio-of-slope method for Th-C alloy irradiated at $80^{\circ} \mathrm{K}$. Resistivity measured at $80^{\circ} \mathrm{K}$. 


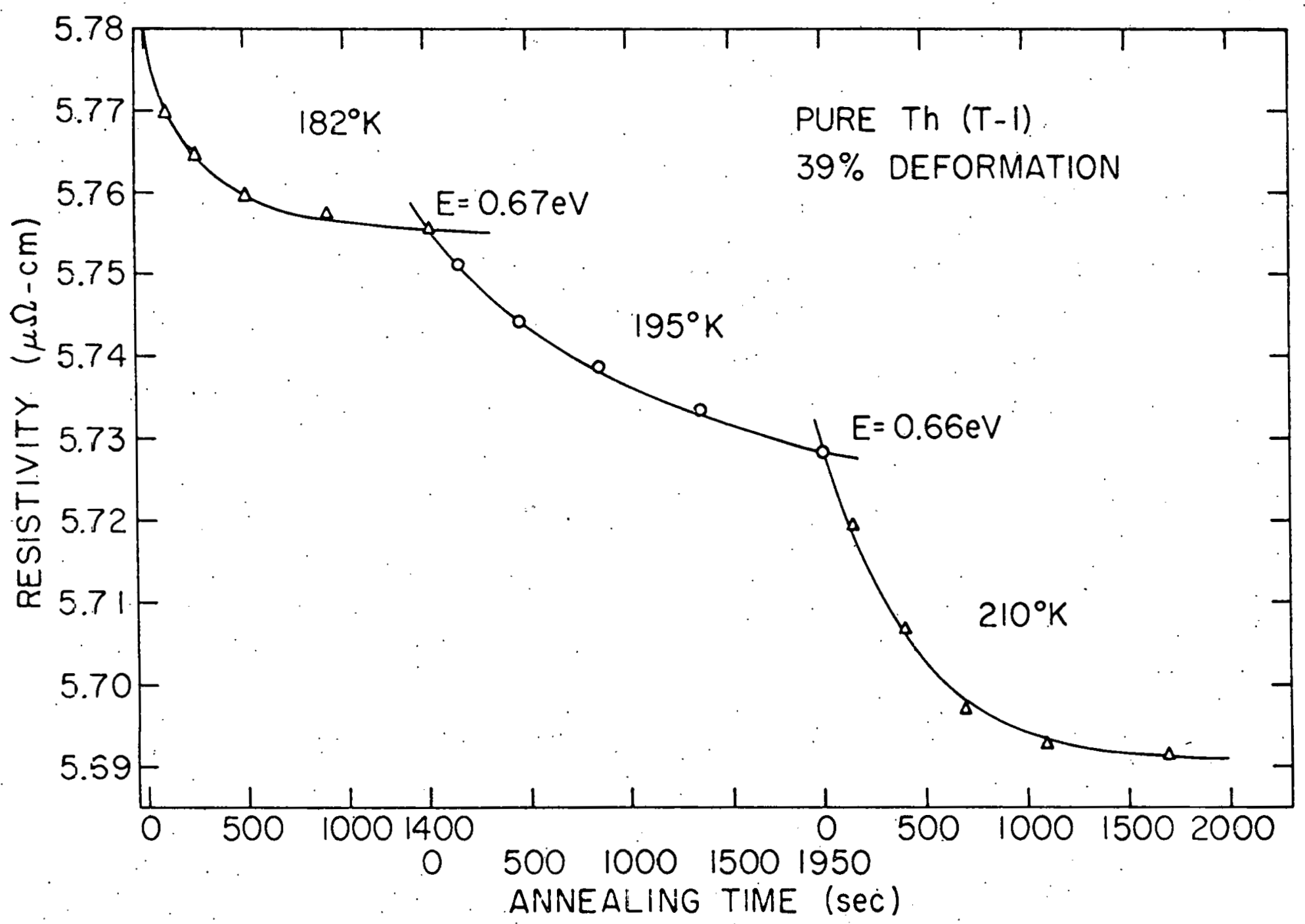

N

Figure 9: Determination of activation energy of stage. II recovery by the ratio-of-slope method for pure Th deformed at $80^{\circ} \mathrm{K}$. Resistivity measured at $80^{\circ} \mathrm{K}$. 


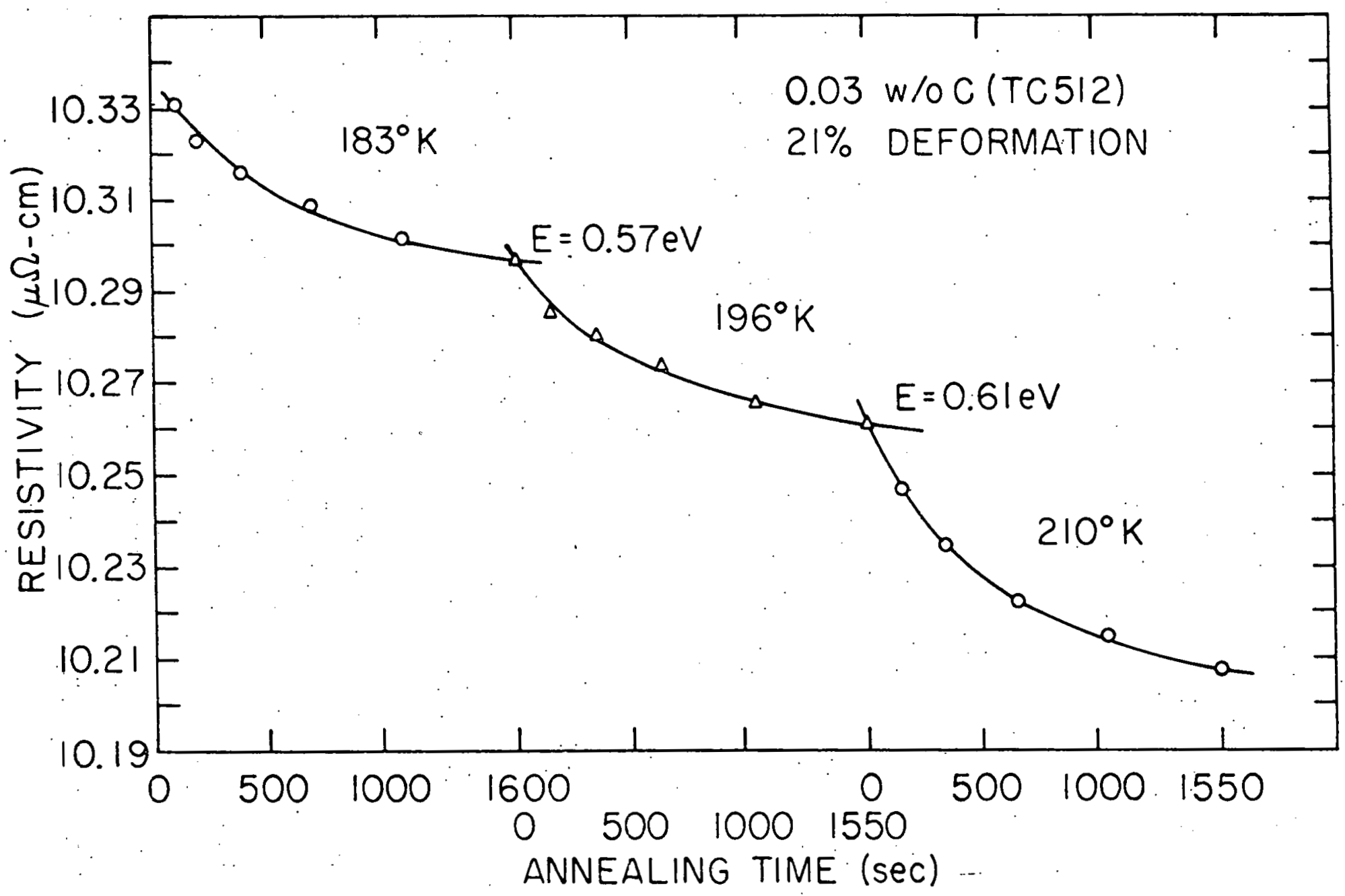

Figure 10. Determination of activation energy of stage II recovery by the ratio-of-slope method for Th-0.03 w/o $\mathrm{C}$ alloy deformed to $21 \%$ at $80^{\circ} \mathrm{K}$. Resistivity measured at $80^{\circ} \mathrm{K}$. 
(7)

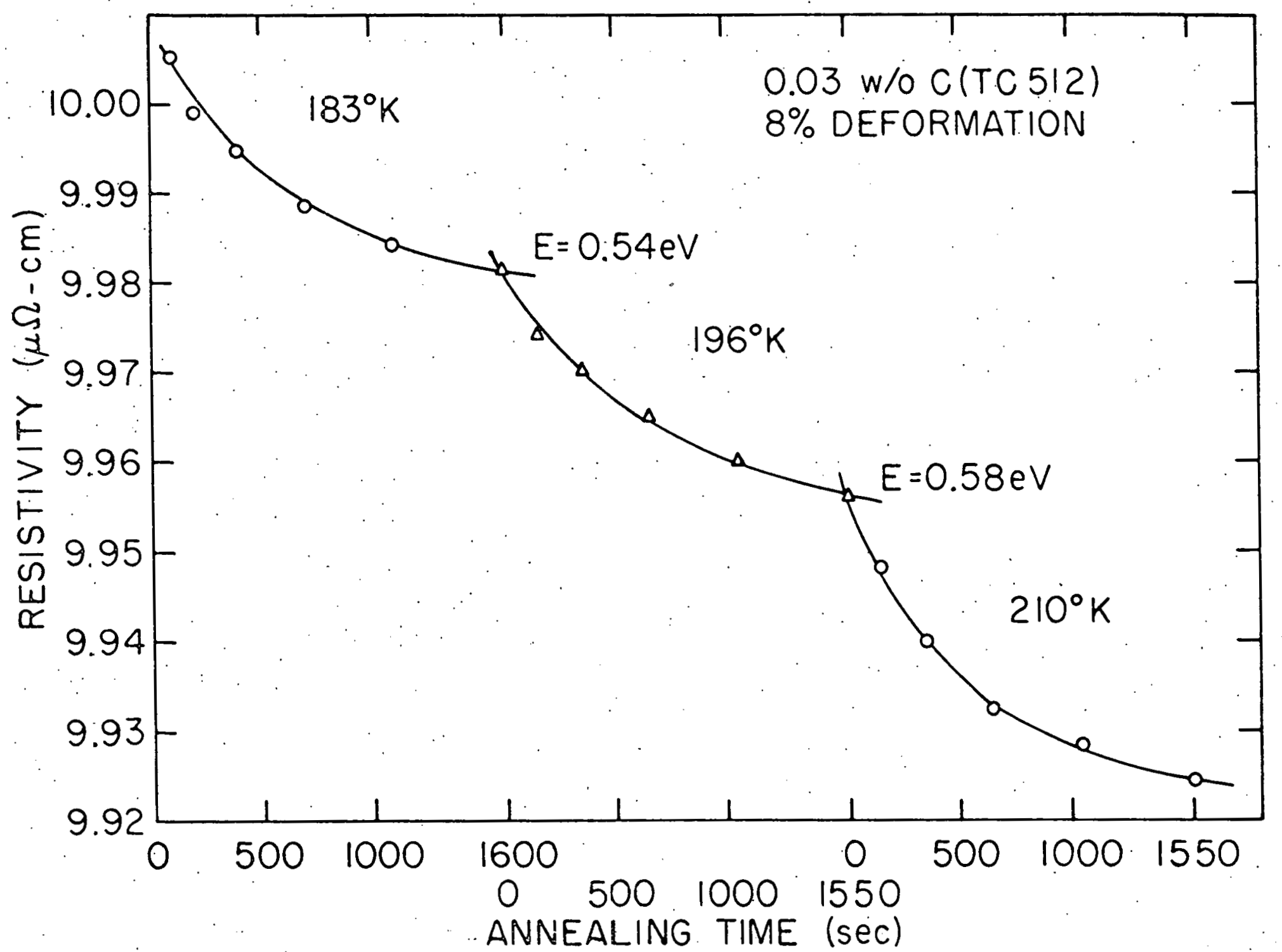

Figure 11. Determination of activation energy of stage II recovery by the ratio-of-slope method for $\mathrm{Th}-0.03 \mathrm{w} / \mathrm{O} \mathrm{C}$. alloy deformed to $8 \%$ at. $80^{\circ} \mathrm{K}$. Resistivity measured at $80^{\circ} \mathrm{K}$. 
Figure 12. Determination of activation energy of stage II recovery by the ratio-of-slope method for Th-0.06 w/O C alloy deformed at $80^{\circ} \mathrm{K}$. Resistivity measured at $80^{\circ} \mathrm{K}$. 


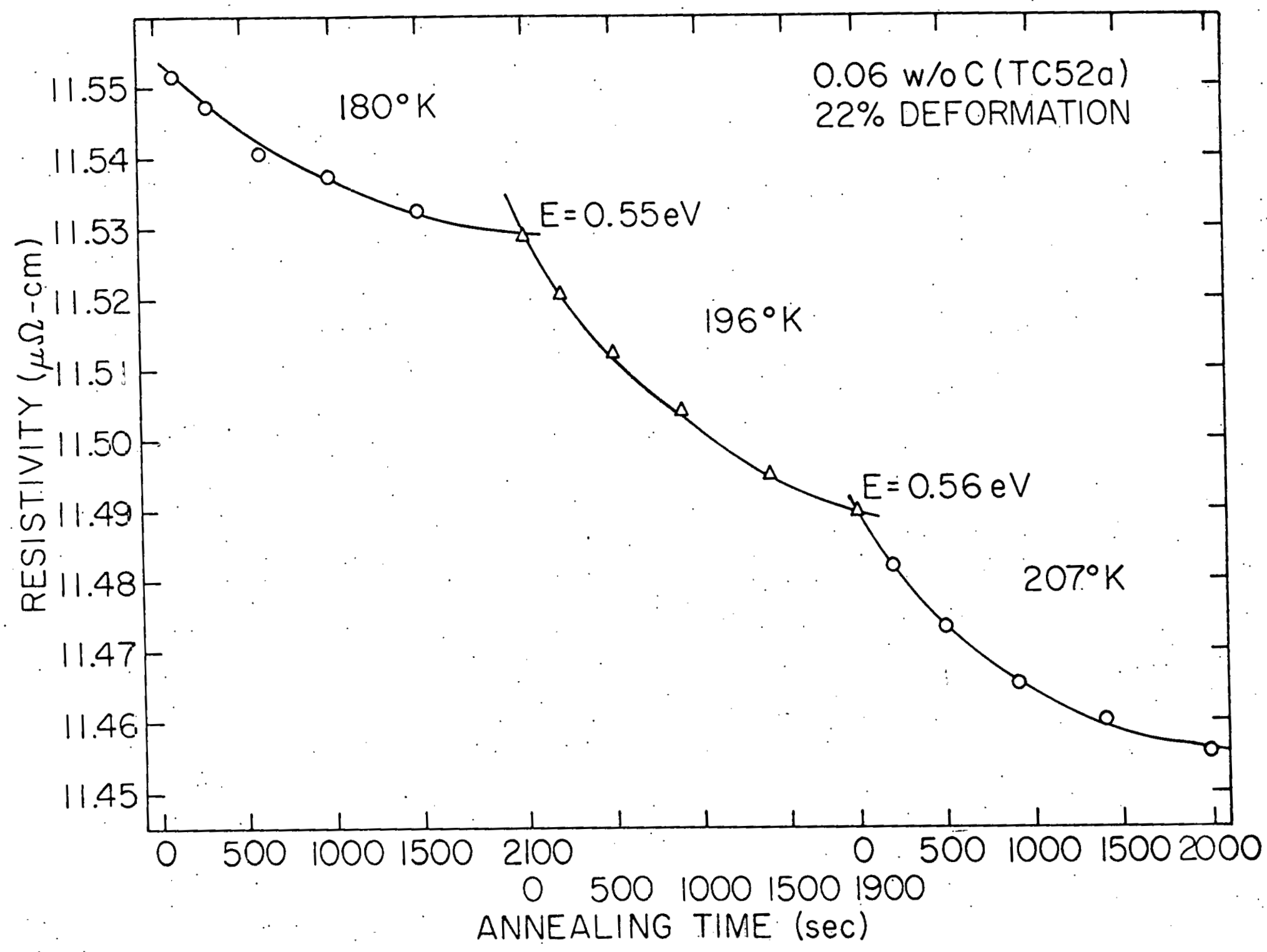

$\omega$ 
values thus obta1ned for $E_{I I}$ from experimental data are listed in Table 2. The experimental error 1nvolved in deducing the activation energies 1 s estimated to be approximately $6 \%$, which is about the same as the mean deviation from the average value of E. In Table 3. only the experimental scatters are shown, which reflect the reproduclbility of the measurement. As the carbon content is increased, the $E_{I I}$ value tends to decrease slightly. This tendency is also seen.in Figures 9, 10, and 12. The dependence of activation energy on deformation, however, is not so obvious. Some examples are shown in Figures 10 and 11. Although the deformation has been increased from 8 to $21 \%$, the change in energy is still only $0.03 \mathrm{eV}$, which is within the uncertainty range.

Figures 13-15 show the determination of activation energy of stage III recovery, $E_{I I I}$, for deformed specimens of $T h$ and ThC alloys by use of the ratio-of-slope method. The results are listed in Table.2. The average values of $E_{I I I}$ are $1.16 \pm 0.08,1.10 \pm 0.10$, and $1.08 \pm 0.08 \mathrm{eV}$ for pure Th, $0.03 \mathrm{w} / \mathrm{O} \mathrm{C}$, and $0.06 \mathrm{w} / \mathrm{O} \mathrm{C}$ alloys, respectively. As in stage II, the stage III activation energy also decreases slightly as the carbon content is increased; otherwise, it is rather independent of deformation.

An alternate method for determining $E$ is the MeechanBrinkman (MB) method. Tf equation (2) is integrated,

$$
\int_{\Delta \rho_{1}}^{\Delta \rho_{2}}-\frac{d(\Delta \rho)}{G(\Delta \rho,(0))}=\left(\int_{t_{1}}^{t_{2}} d t\right) K_{0} \exp (-E / k T)
$$


Table 2. Average activation energy obtained by ratio-of-slope method in deformed thorium

\begin{tabular}{|c|c|c|c|c|c|}
\hline \multicolumn{3}{|c|}{ Stage II } & \multicolumn{3}{|c|}{ Stage III } \\
\hline $\begin{array}{l}\text { Specimen } \\
\text { (number) }\end{array}$ & $\overline{\mathrm{E}}_{\mathrm{II}}(\mathrm{eV})$ & $\begin{array}{l}\text { Deformation } \\
\qquad(\%)\end{array}$ & $\begin{array}{l}\text { Specimen } \\
\text { (number) }\end{array}$ & $\overline{\mathrm{E}}_{\mathrm{III}}(\mathrm{eV})$ & $\underset{(\%)}{\operatorname{Deformation}}$ \\
\hline$T-1 \quad(12-1)$ & $0.57 \pm 0.07$ & 33 & $T-1(8-3)$ & 1.19 & 17 \\
\hline $\mathrm{T}-1(12-2)$ & $0.59 \pm 0.07$ & 30 & T-1 (12-1) & 1.12 & 33 \\
\hline$T-1 \quad(12-3)$ & $0.67 \pm 0.01$ & 39 & $T-1(12-2)$ & $1.10 \pm 0.01$ & 30 \\
\hline $\mathrm{T}-1$ (158) & $0.62 \pm 0.04$ & 41 & $\begin{array}{ll}T-1 & (168) \\
T-1 & (142)\end{array}$ & $\begin{array}{l}1.27 \\
1.27\end{array}$ & $\begin{array}{l}13 \\
27\end{array}$ \\
\hline \multicolumn{3}{|c|}{$\overline{\mathrm{E}}_{I I}=0.61 \pm 0.07$} & \multicolumn{3}{|c|}{$\overline{\mathrm{E}}_{I I I}=1.16 \pm 0.08$} \\
\hline $\operatorname{TC512}(27-i)$ & $0.56 \pm 0.06$ & 21 & $\operatorname{TC} 512(27-1)$ & $1.12 \pm 0.03$ & 21 \\
\hline $\operatorname{TC512}(27-5)$ & $0.56 \pm 0.07$ & 8 & $\operatorname{TC} 512(27-7)$ & $1.08 \pm 0.10$ & 21 \\
\hline $\operatorname{TC512}(27-7)$ & $0.59 \pm 0.02$ & 21 & & & \\
\hline Tc512 (166) & $0.59 \pm 0.05$ & 13 & & & . \\
\hline $\operatorname{To512}$ (158) & $0.59 \pm 0.03$ & 7 & & & \\
\hline Total Ave: & $I I=0.57 \pm 0$ & 0.07 & & III $=1.10 \pm$ & 0.10 \\
\hline $\operatorname{T} 252 a(18-1)$ & $0.55 \pm 0.03$ & 28 & $\operatorname{TC52a}(12-1)$ & 1.08 & 15 \\
\hline TC52a $(18-2)$ & $0.56 \pm 0.01$ & 22 & $\begin{array}{l}\text { TC52a }(18-1) \\
\text { TC52a }(142) .\end{array}$ & $\begin{array}{l}1.12 \pm 0.04 \\
1.03 \pm 0.10\end{array}$ & $\begin{array}{l}28 \\
19\end{array}$ \\
\hline Total Ave: $\overline{\mathrm{E}}$ & $I I=0.55 \pm 0$ & 0.07 & $\because$ & $I I I=1.08 \pm$ & 0.08 \\
\hline
\end{tabular}




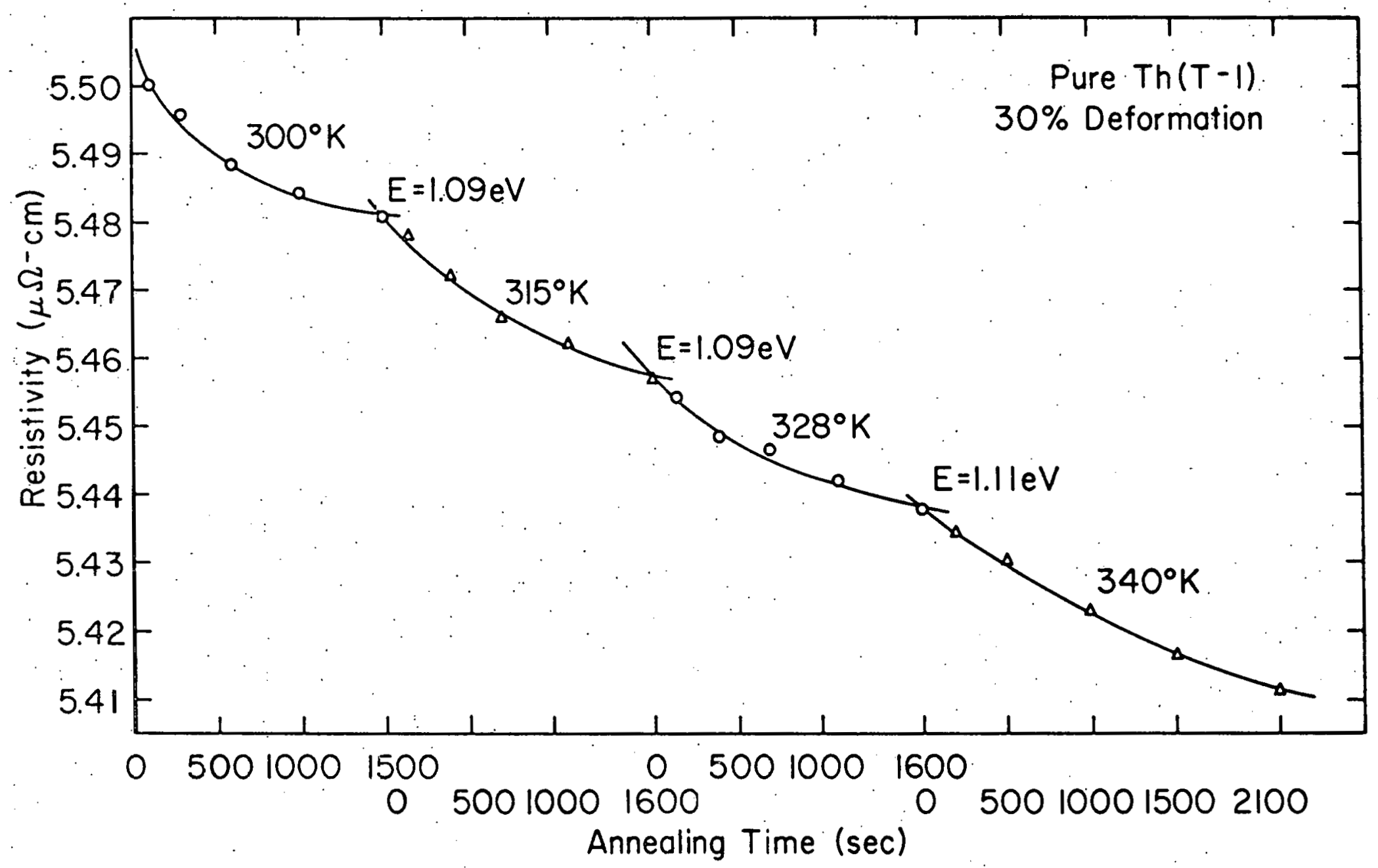

Figure 13. Determination of activation energy of stage III recovery by the ratio-of-slope method for pure $\mathrm{Th}$ deformed at $80^{\circ} \mathrm{K}$. Resist1vity measured at $80^{\circ} \mathrm{K}$. 
Figure 14. Determination of activation energy of stage III recovery by the ratio-of-slope method for Th-0.03 w/o C alloy deformed at $80^{\circ} \mathrm{K}$. Resistivity measured at $80^{\circ} \mathrm{K}$. 


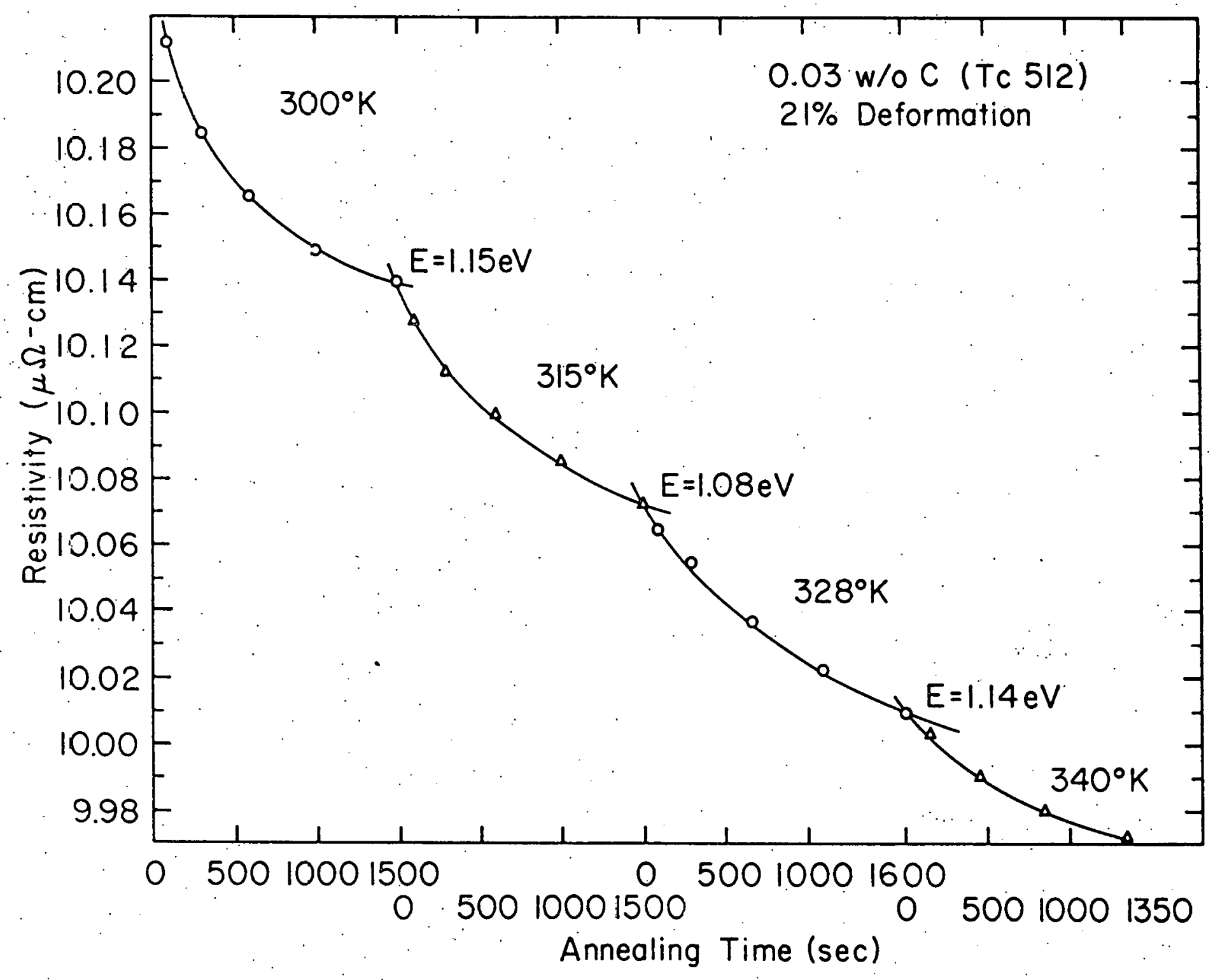

$\omega$ 


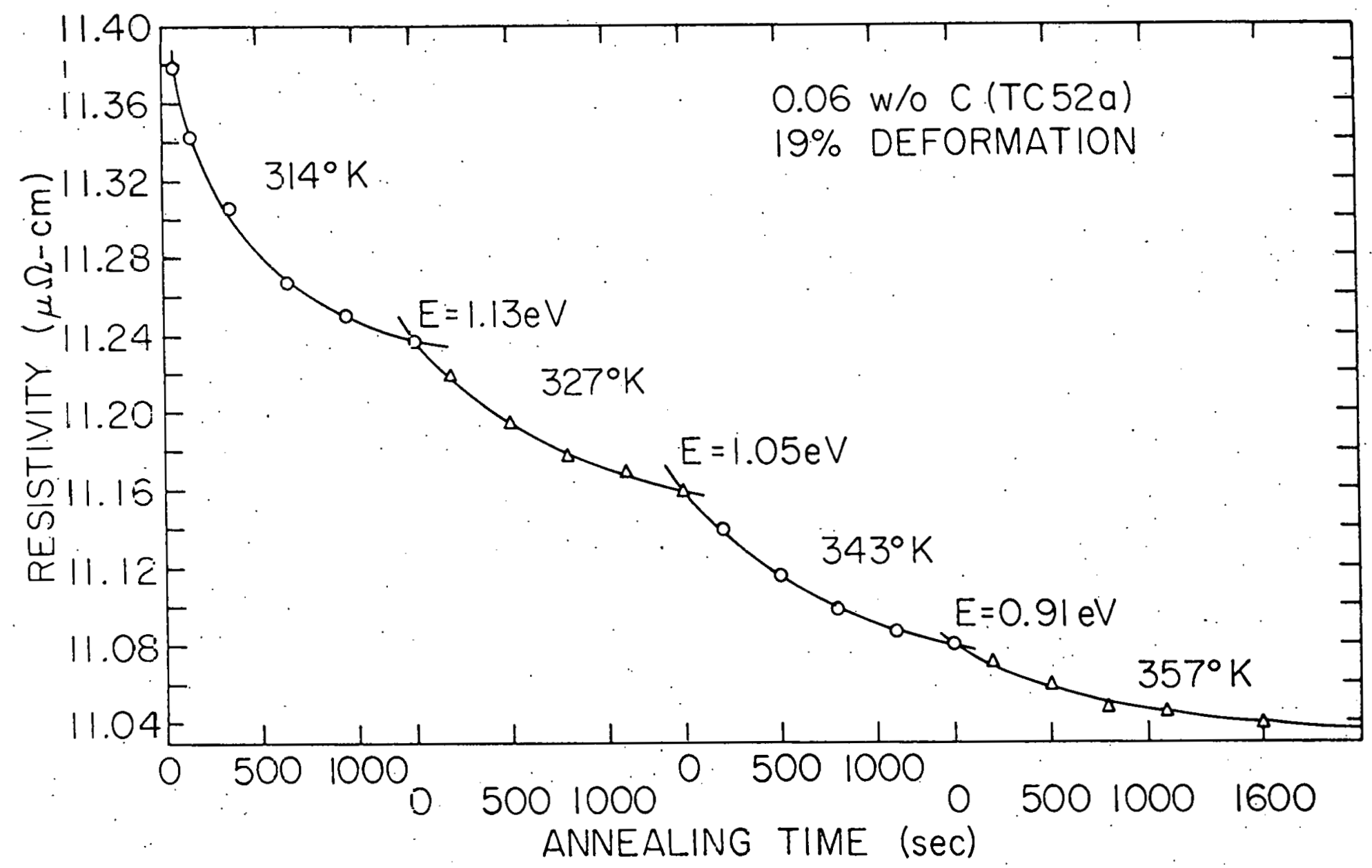

Figure 15. Determination of activation energy of stage III.recovery by the ratio-of-slope method for $\mathrm{Th}-0.06 \mathrm{w} / \mathrm{O} \mathrm{C}$ alloy deformed at $80^{\circ} \mathrm{K}$. Resistivity measured at $80^{\circ} \mathrm{K}$. 
The lefthand side of equation (4) is a pure number because the integral between the values of two flxed limits is a constant. Thus, we obtain an expression

$$
\Delta t \exp \left(-E / k^{T} T\right)=\text { constant }
$$

where $\Delta t$ is the time interval between the two $\Delta \rho$ values. Utilizing equation (5) it is possible to superimpose the isochronal and isothermal recovery curves provided that the two specimens have the same initial damage stage. Under this condition, we further have

$$
\Delta t_{c} \exp \left(-E / k T_{c}\right)=\Delta t_{i} \exp \left(-E / k T_{i}\right)
$$

where the subscripts $c$ and 1 denote the isochronal and isothermal annealing processes, respectively. For the isothermal process, $\mathrm{T}_{1}$ is a constant; and for the isochronal process, $\Delta t_{c}$ is a constant. Hence the following equation can be deduced from equation (6)

$$
\text { In } \Delta t_{i}=\text { constant }-E / \mathrm{kT}_{\mathrm{c}} \text {. }
$$

Based on equation (7), a graph of In $\Delta t_{1}$ vs $1 / T_{c}$ should display a straight line with the slope being equal to - E/k.

The results of applying the MB method for determining the stage III activation energy to the recovery data obtained from irradiated specimens are shown in Figures 16-18. The average activation energies obtalned from the MB method for pure Th and the w/o C-Th alloy are $0.98 \pm 0.01$ and $0.95 \pm 0.03 \mathrm{eV}$, respectively.

A third method known as the cross-cut method is based on equation (2) by using two or more isothermal annealing curves, 
Figure 16. Determination of activation energy of stage.III recovery by the MB method for pure Th irradiated at $80^{\circ} \mathrm{K}$ to a fluence of $1.3 \times 10^{18} \mathrm{n} / \mathrm{cm}^{2}$ $(E>0.1 \mathrm{MeV}) . \mathrm{T}_{1}, \mathrm{~T}_{\mathrm{c}}$, and $\Delta \mathrm{t}_{1}$ are as defined in equation (6). 


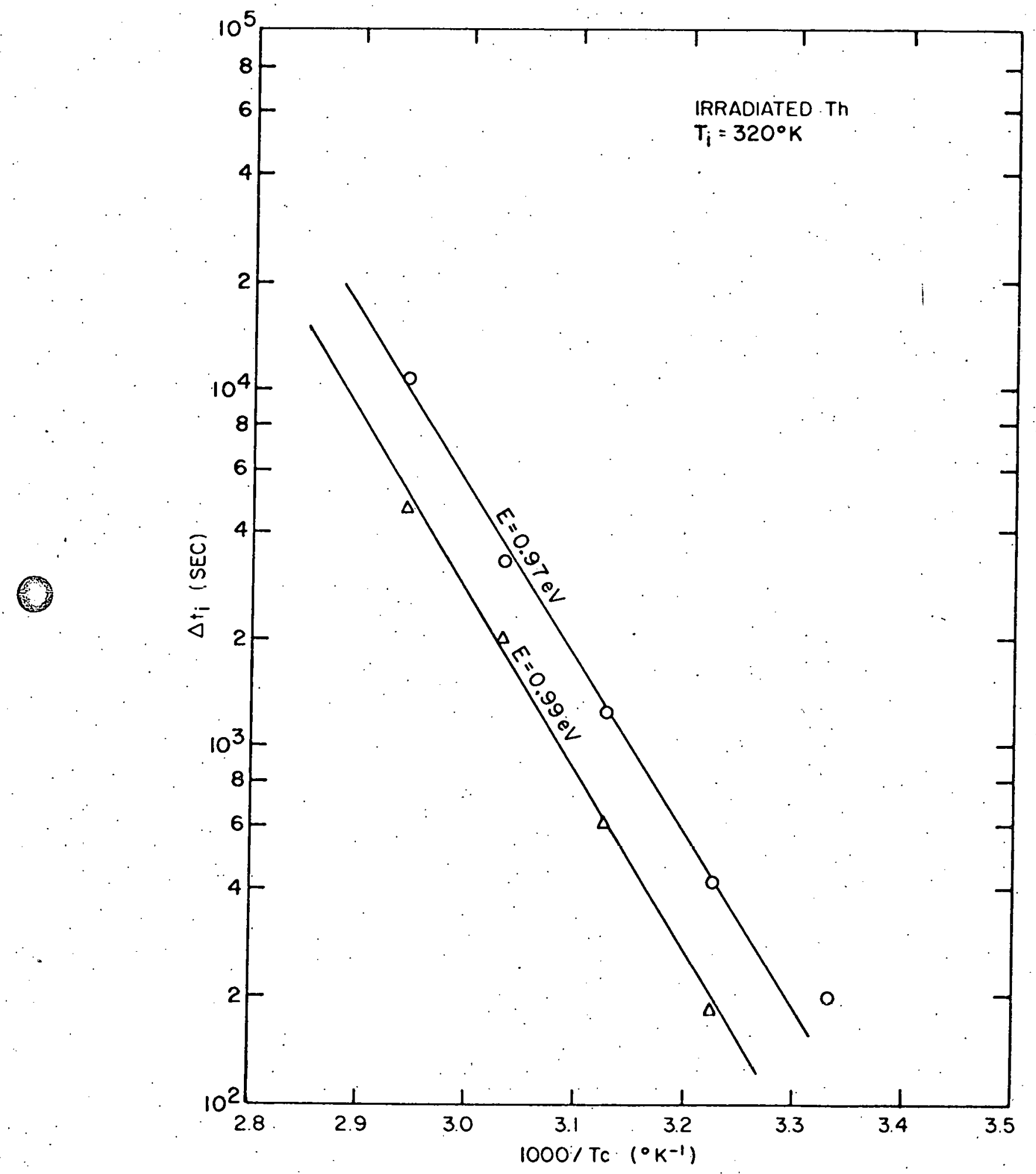


Figure 17. Determination of activation energy of stage III recovery by the MB method for $\mathrm{Th}-0.03 \mathrm{w} / \mathrm{O} \mathrm{C}$ alloy Irradiated at $80^{\circ} \mathrm{K}$ to $1.3 \times 10^{18} \mathrm{~m} / \mathrm{cm}^{2}$ $(E>0.1 \mathrm{MeV})$... The isothermal annealing temperature is $320^{\circ} \mathrm{K}$. 


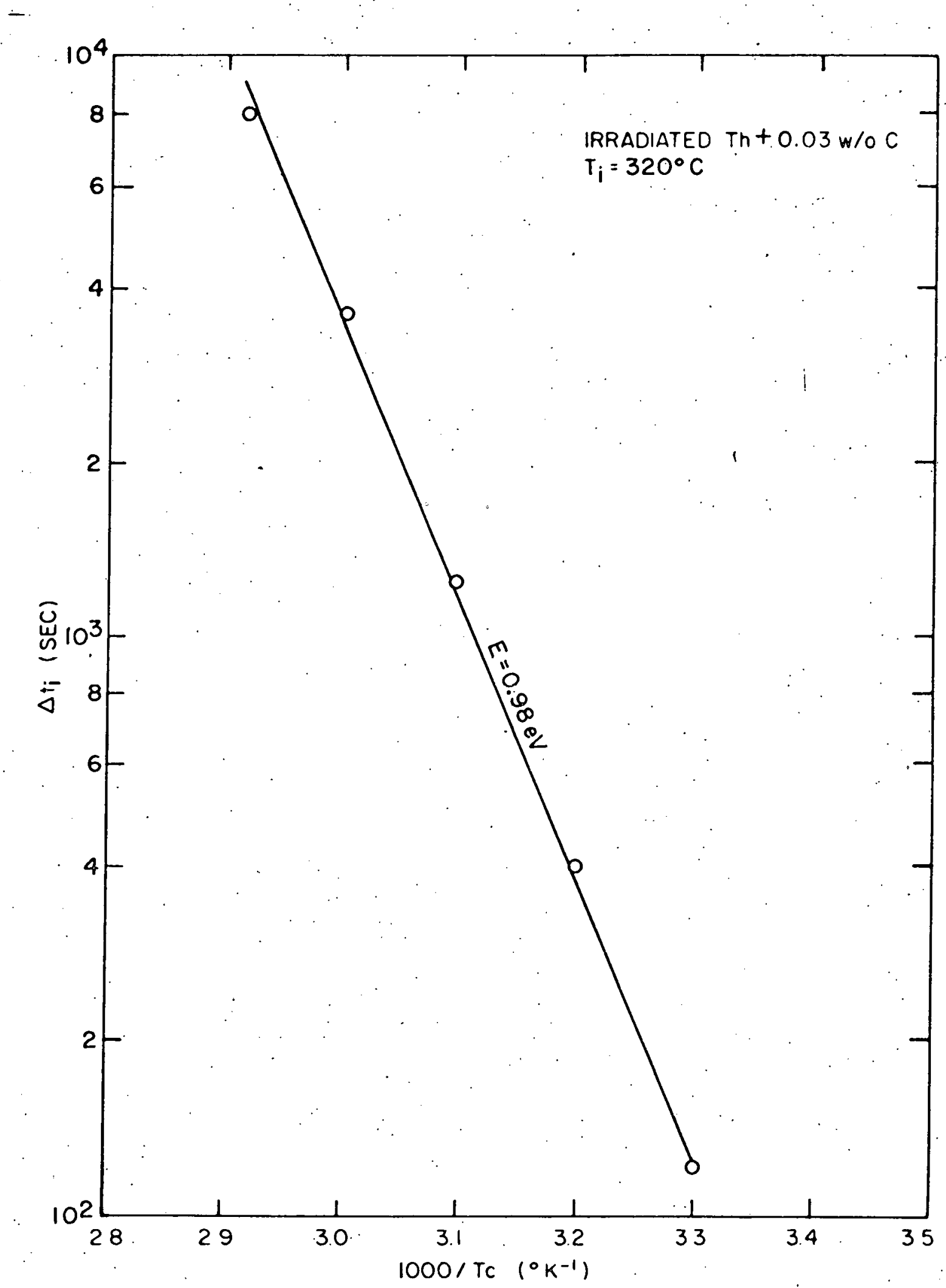


Figure 18. Determination of activation energy of stage III recovery by the $\mathrm{MB}$ method for $\mathrm{Th}-0.03 \mathrm{w} / \mathrm{O} \mathrm{C}$ alloy irradiated at $80^{\circ} \mathrm{K}$ to $1.3 \times 10^{18} \mathrm{n} / \mathrm{cm}^{2}$ ( $E>0.1 \mathrm{MeV})$. "The isothermal annealing temperature is $310^{\circ} \mathrm{K}$. 

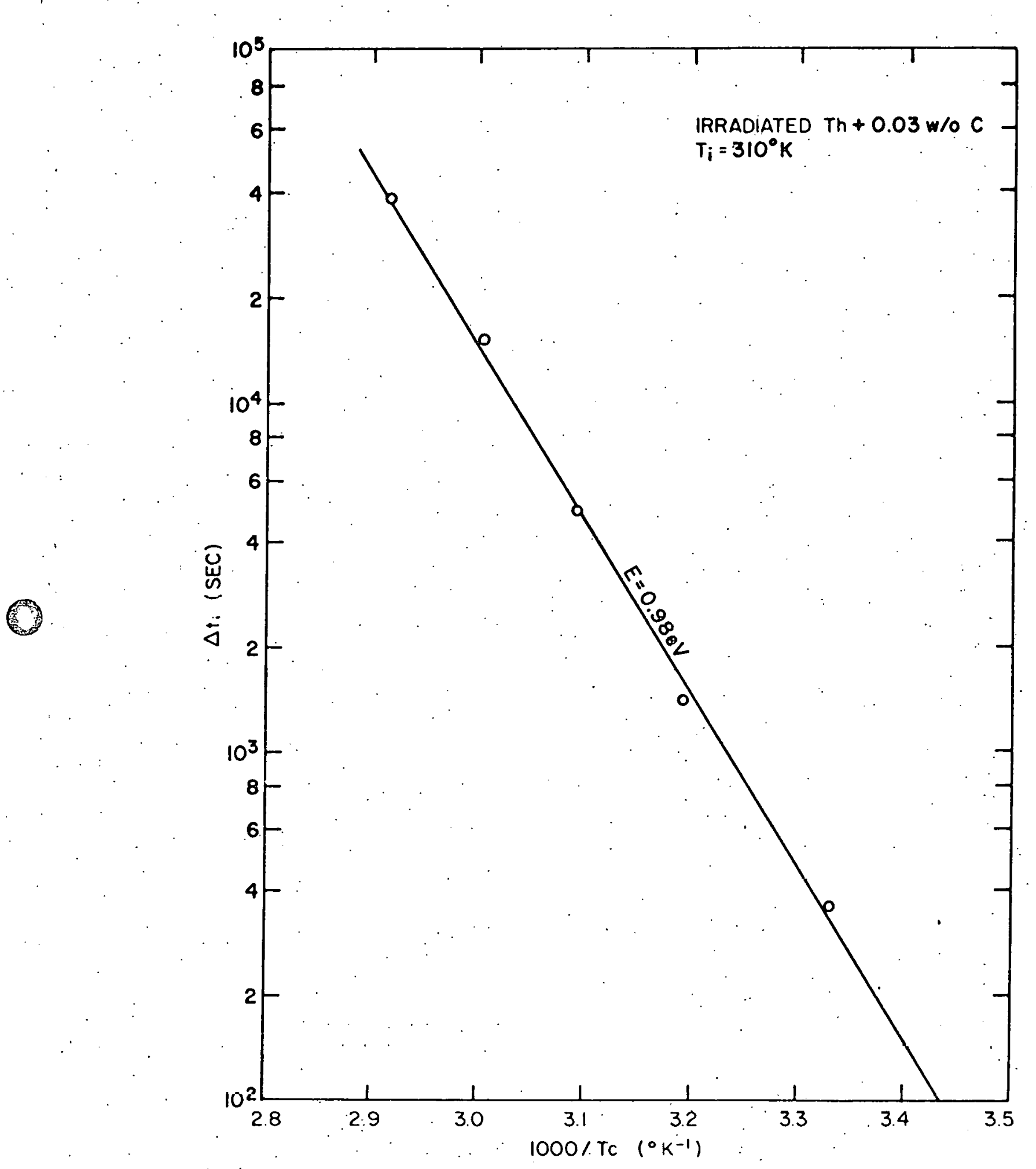
on a set of Identical specimens, 1 .e., specimens conta1ning the same inftial concentration of defects. In this case, equation (5) can be rewritten as:

$$
t_{1} \exp \left[-E / k T_{1}\right]=\text { constant: } \equiv C
$$

where $t_{i}$ is the time required to reach a constant value of $\Delta \rho$ at annealing temperature $T_{i}$. When the cut crosses several curves, the times given by the intersecting points are related to the pertinent temperatures by

$$
\ln \left(t_{i}\right)=\ln \mathrm{C}+\mathrm{E} / \mathrm{kT}_{i}
$$

Equation ( 9 ) enables $E$ to be evaluated from the slope of a straight line fitting the data points in the plot of log $t_{i}$ against $1 / \mathrm{T}_{1}$. If a cut is taken at another ordinate point in the $\Delta \rho$ vs $t_{1}$ plot, only the constant $c$ is altered in equation (9) and the lines described by this equation should be parallel if the process features a single activation energy. The results of applying this method for determining the stage III activation energy in the irradiated Th-C specimens are shown in Figure 19. By using a least-square fit, the activation energy is estimated. The two stralght lines in Figure 19 are not exactiy parallel. The deduced activation energy, $E$, are 1.01 and $0.94 \mathrm{eV}$, which are close to the values deduced from other methods.

A comparison of all deduced average values for $E$. from the three methods is given in Table 3, which indicates that, 
Figure 19. Determination of activation energy of stage III recovery by the cross-cut method for Th-0.03 w/O C ailoy Irradiated at $80^{\circ} \mathrm{K}$ to $1.3 \times 10^{18}$ $\mathrm{n} / \mathrm{cm}^{2}(\mathrm{E}>0.1 \mathrm{MeV}) . \mathrm{T}_{i}$ and $\mathrm{t}_{i}$ are as defined in equation (8). f is the normalized resistivity value. 


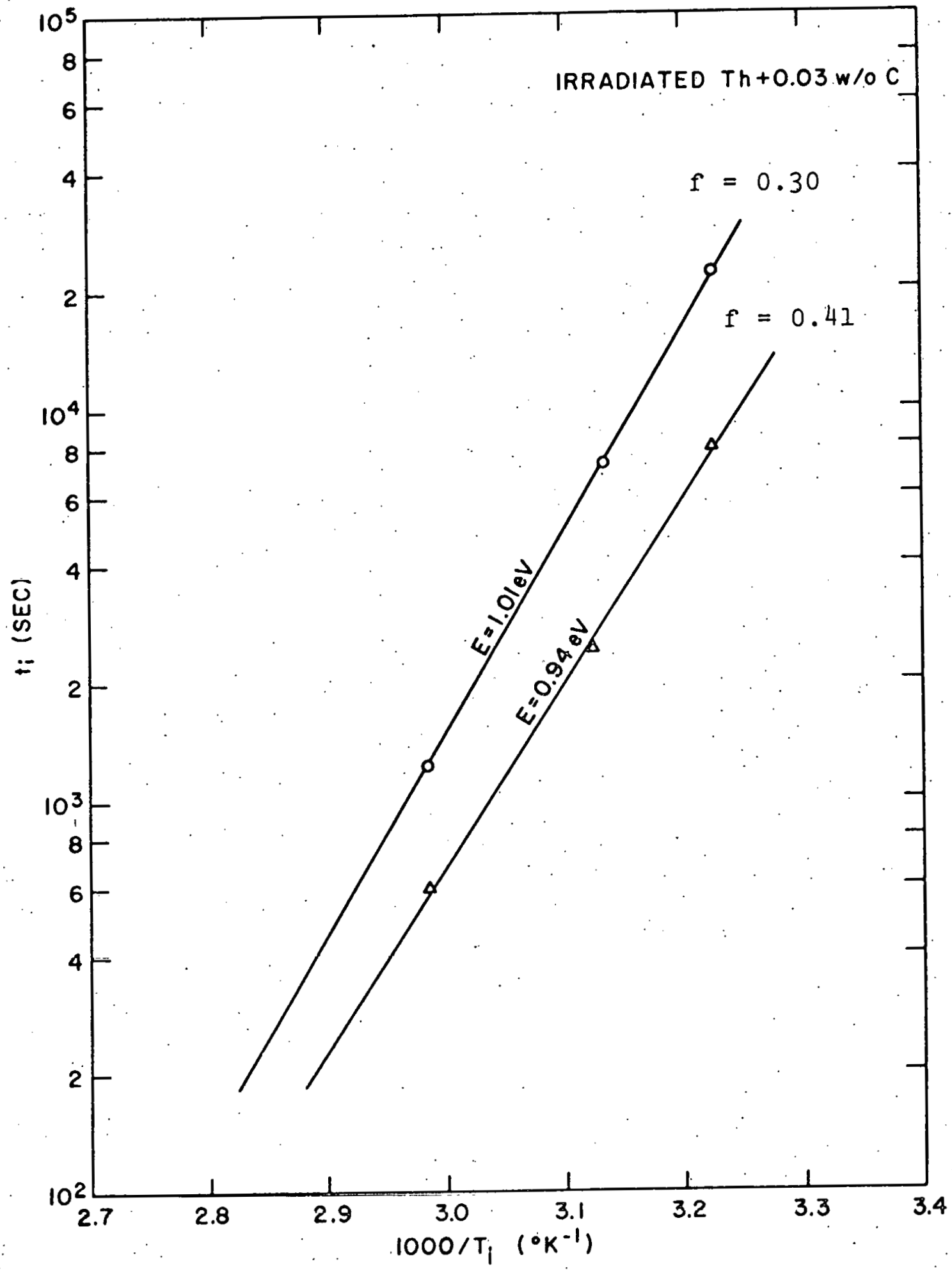


Table 3. Average activation energy for stage III recovery. in neutron-irradiation thorium

\begin{tabular}{|c|c|c|c|c|c|}
\hline \multicolumn{3}{|c|}{ Pure Th $(T-1)$} & \multicolumn{3}{|c|}{$\mathrm{Th}-0.03 \mathrm{w} / \mathrm{O} \mathrm{C}(\mathrm{TC} 512)$} \\
\hline Method & $\begin{array}{l}\text { Number of } \\
\text { indepencient } \\
\text { specimens } \\
\end{array}$ & $\begin{array}{l}\text { Average } \\
\text { activation } \\
\text { energy, } \\
\bar{E}_{\text {III }}(\mathrm{eV})\end{array}$ & Method & $\begin{array}{l}\text { Number of } \\
\text { Independent } \\
\text { specimens }\end{array}$ & $\begin{array}{l}\text { Average } \\
\text { activation } \\
\text { energy, } \\
\bar{E}_{I I I}(\mathrm{eV})\end{array}$ \\
\hline Ratio-of-slope & 1 & $1.14 \pm 0.04$ & Ratio-of-slope & 2 & $1.07 \pm 0.06$ \\
\hline Meechan-Erinkman & 2 & $0.98 \pm 0.01$ & $\begin{array}{l}\text { Meechan-Brinkman } \\
\text { Cross-cut }\end{array}$ & $\begin{array}{l}4 \\
\because 3\end{array}$ & $\begin{array}{l}0.95 \pm 0.03 \\
0.98 \pm 0.04\end{array}$ \\
\hline
\end{tabular}

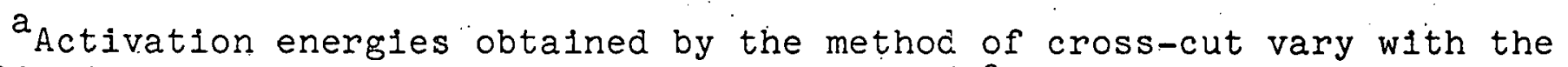
nomalized resistivity, f. They increase from 0.78 to $1.07 \mathrm{eV}$ as $\mathrm{f}$ values change from 0.6 to 0.2 . Due to the scattering of datapoints, this value was not obtained for pure thorium. 


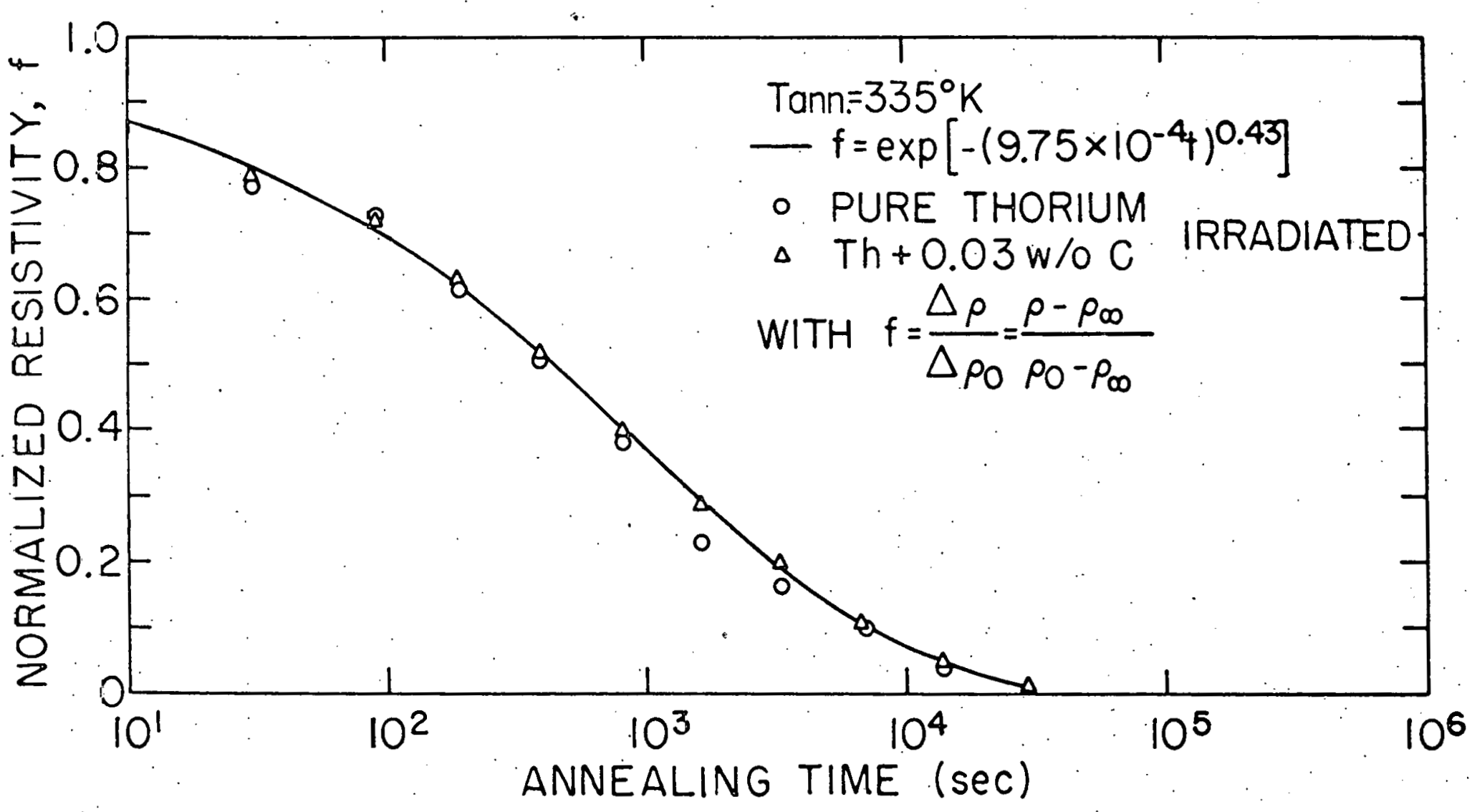

Figure 20. Isothermal annealing curves of stage III for pure $T h$ and Th-0.03 w/0 C alloy 1rradiated at $80^{\circ} \mathrm{K}$ to $1.3 \times 10^{18} \mathrm{n} / \mathrm{cm}^{2}$. $(E>0.1 \mathrm{MeV})$ : The annealing temperature is $335^{\circ} \mathrm{K}$. 


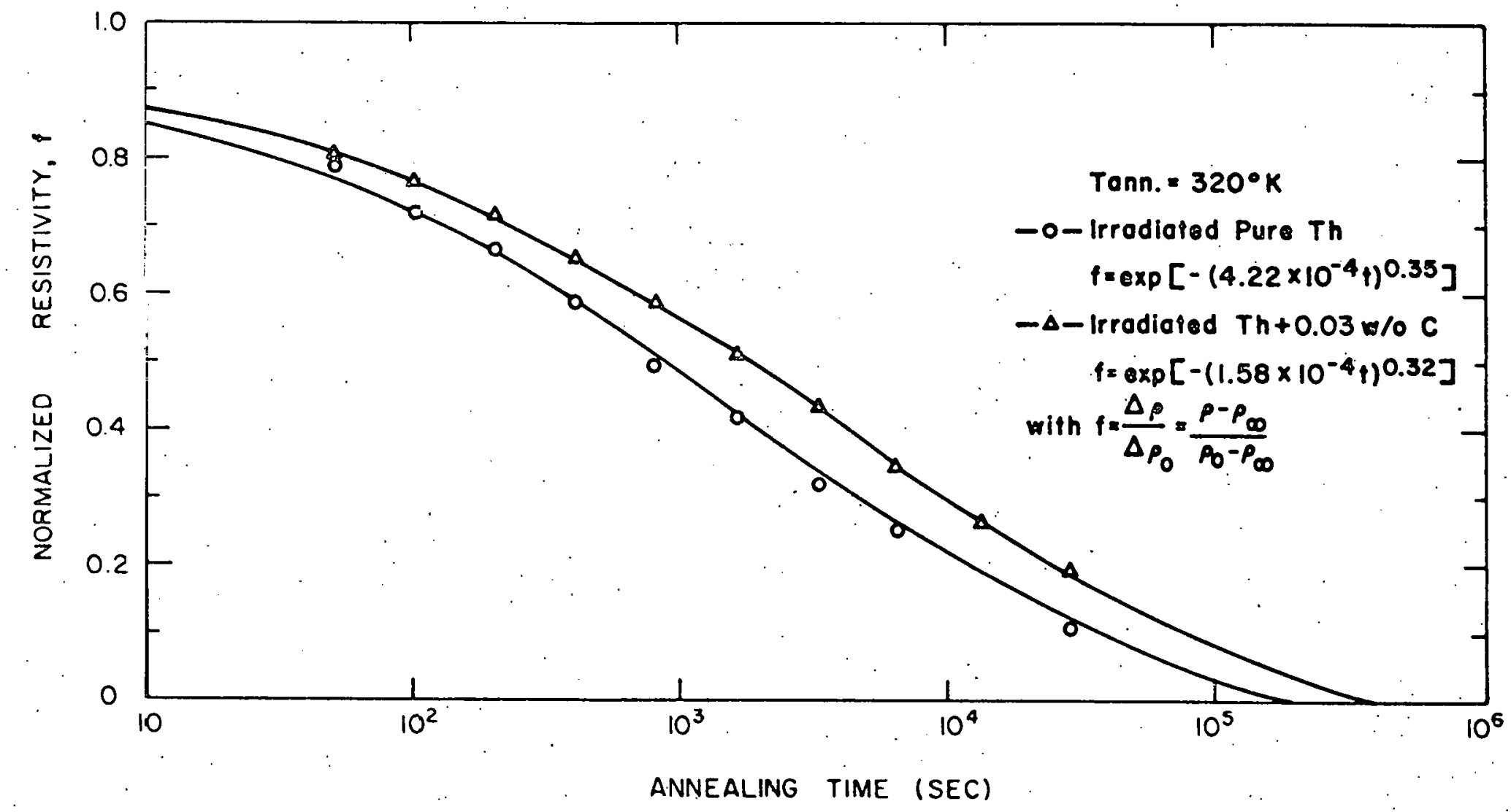

Figure 21. Isothermal annealing curves of stage III for pure Th and Th-0.03 w/o C alloy irradiated at $80^{\circ} \mathrm{K}$ to $1.3 \times 10^{18} \mathrm{n} / \mathrm{cm}^{2}$ ( $E>0.1 \mathrm{MeV})$. The annealing temperature is $320^{\circ} \mathrm{K}$. 


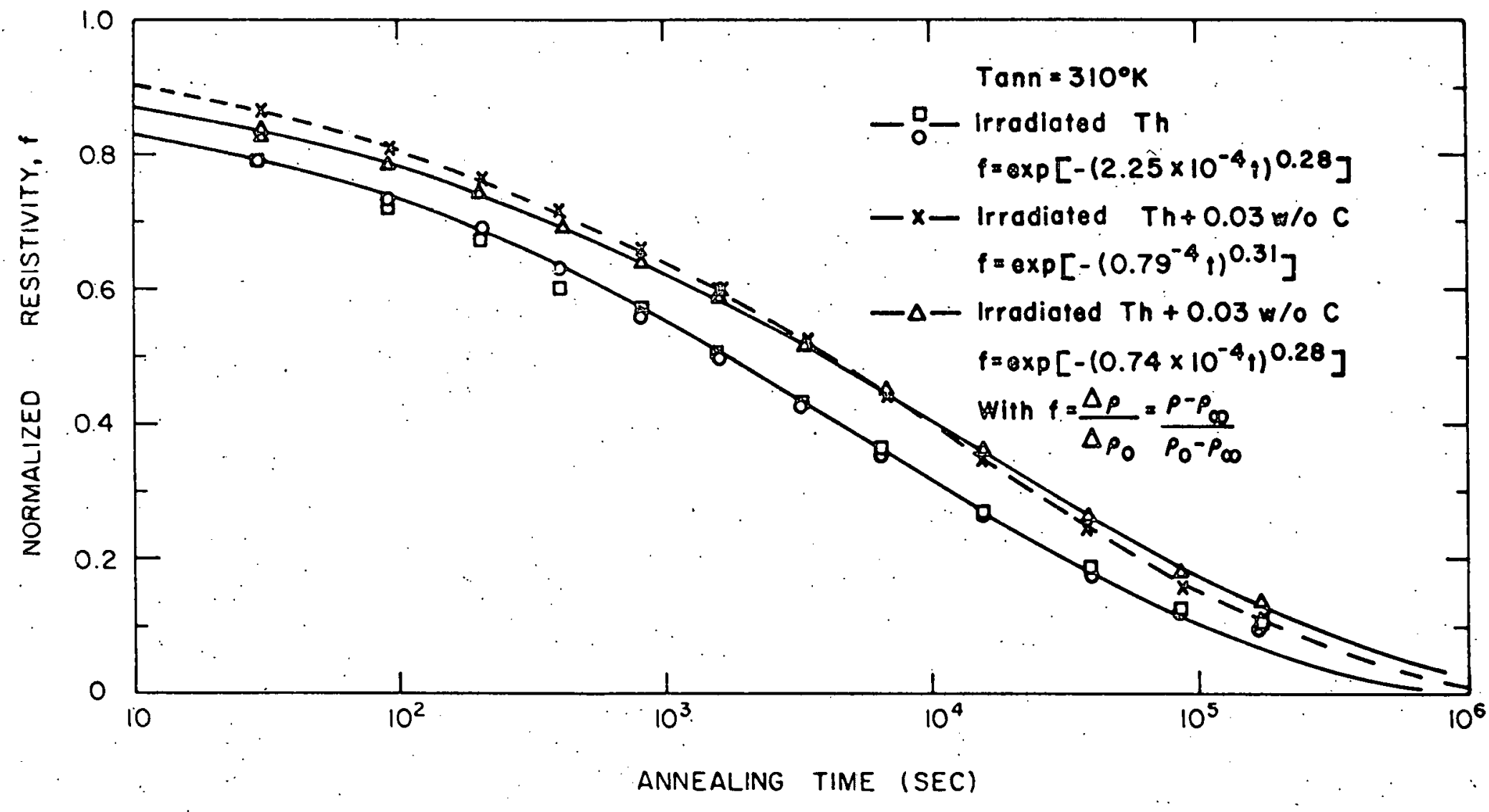

F1gure 22. Isothermal annealing curves of stage III for pure Th and Th-0.03 w/o C alloy irradiated at $80^{\circ} \mathrm{K}$ to $1.3 \times 10^{18} \mathrm{n} / \mathrm{cm}^{2}$ $(\dot{E}>0.1 \mathrm{MeV})$. The annealing temperature is $310^{\circ} \mathrm{K}$. 


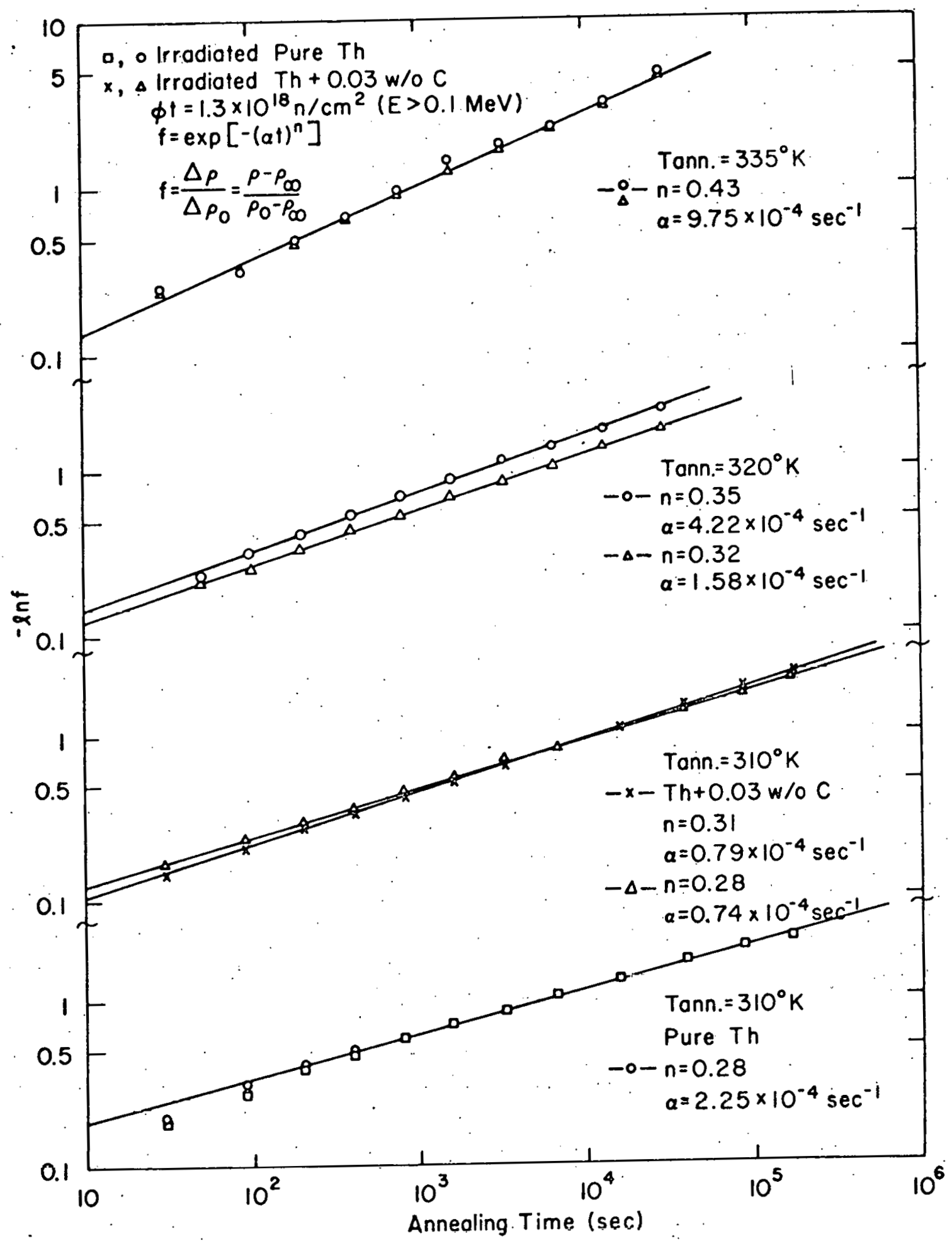

Figure 23. Log-log plots of in $1 / f$ versus annealing time for irradiated specimens annealed at different temperatures. The curves are shifted along the ordinate relative to each other for clarity. .. 
the values deduced by the $M B$ method are somewhat lower than values deduced by the rat1o-of-slope method.

\section{Isothermal Annealing and Kinetics}

For the purpose of analyzing the annealing kinetics and obtaining activation energies by the MB and cross-cut methods, irradiated $T h$ and the Th-C alloy were annealed isothermally In three different temperatures close to the stage III peak. position, $320^{\circ} \mathrm{K}$. Figures 20,21 , and 22 show the results of 1sothermal annealing for Th and the $0.03 \mathrm{w} / 0 \mathrm{C}-\mathrm{Th}$ alloy at $335^{\circ}, 320^{\circ}$, and $310^{\circ} \mathrm{K}$, respectively. In these figures, the normalized resistivity or the fractional resistivity remained in stage III, $f=\frac{\Delta \rho}{\Delta \rho_{0}}=\frac{\rho-\rho_{\infty}}{\rho_{0}-\rho_{\infty}}$, is plotted against the annealing time, where $\rho$ is the measured resistivity at time $t$, jo the resistivity at the beginning of stage III recovery, $\rho_{\infty}$ the resistivity at the end of stage III. Values for $\rho_{0}$ and $\rho_{\infty}$ were determined from the isochronal recovery curves. The smooth curves in Figures 20-22 were calculated from the Avrami empirical equation (69),

$$
f=\exp \left[-(\alpha t)^{n}\right]
$$

where $\alpha$ and $n$ are constants independent of $f$ (and thus of t) at constant temperature. To determine $n$ and $\alpha$, the factor $\log [-1$ inf $]$ was plotted against $\log t$, as shown in Figure 23. The deduced values for the exponent $\mathrm{n}$ are 
$0.28-0.31,0.32-0.35$, and 0.43 for annealing at 310 , 320 , and $335^{\circ} \mathrm{K}$, respectively, showing a slight increase with Increasing temperature, but an independence on the carbon content. Combining Figures 20-22, Figures 24 and 25 reveal the temperature effect on the isothermal annealing in pure Th and the $0.03 \mathrm{w} / \mathrm{o}$ C-Th alloy. The curves for pure Th do not fit the data points very well at the beginning of the anneal; the fitting was satisfactory thereafter.

Isothermal anneals at $335^{\circ} \mathrm{K}$ were also performed for cold-worked Th-0.03 w/O.C alloy to different strains. The results are shown in Figure 26, where the normalized resistivity at $78^{\circ} \mathrm{K}, \mathrm{f}$, is plotted against annealing time. A good fit to the empirical equation $f=\exp \left[-(\alpha t)^{n}\right]$ was obtained. Values for the exponent $n$ were determined by plotting $\log (-\ln f)$ against $\log t$ in Figure 27. The deduced values for $\mathrm{n}$ are 0.55 and 0.60 for deformed $\mathrm{Th}-0.03$ w/o $\mathrm{C}$ : alloy deformed to $13 \%$ and $5 \%$, respectively. 


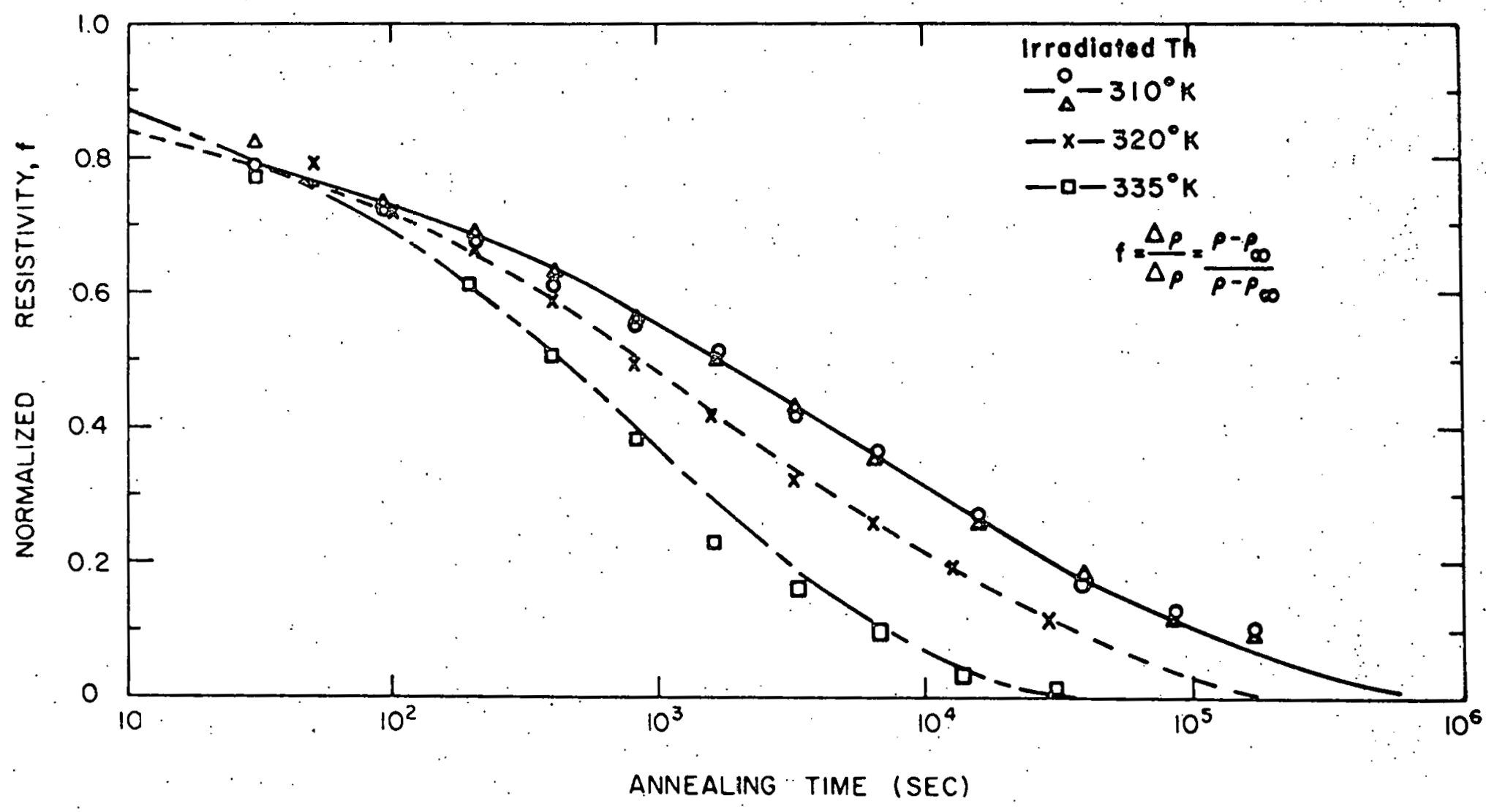

Figure 24. Isothermal annealing curves for Irradiated pure Th specimens at different_temperatures. 


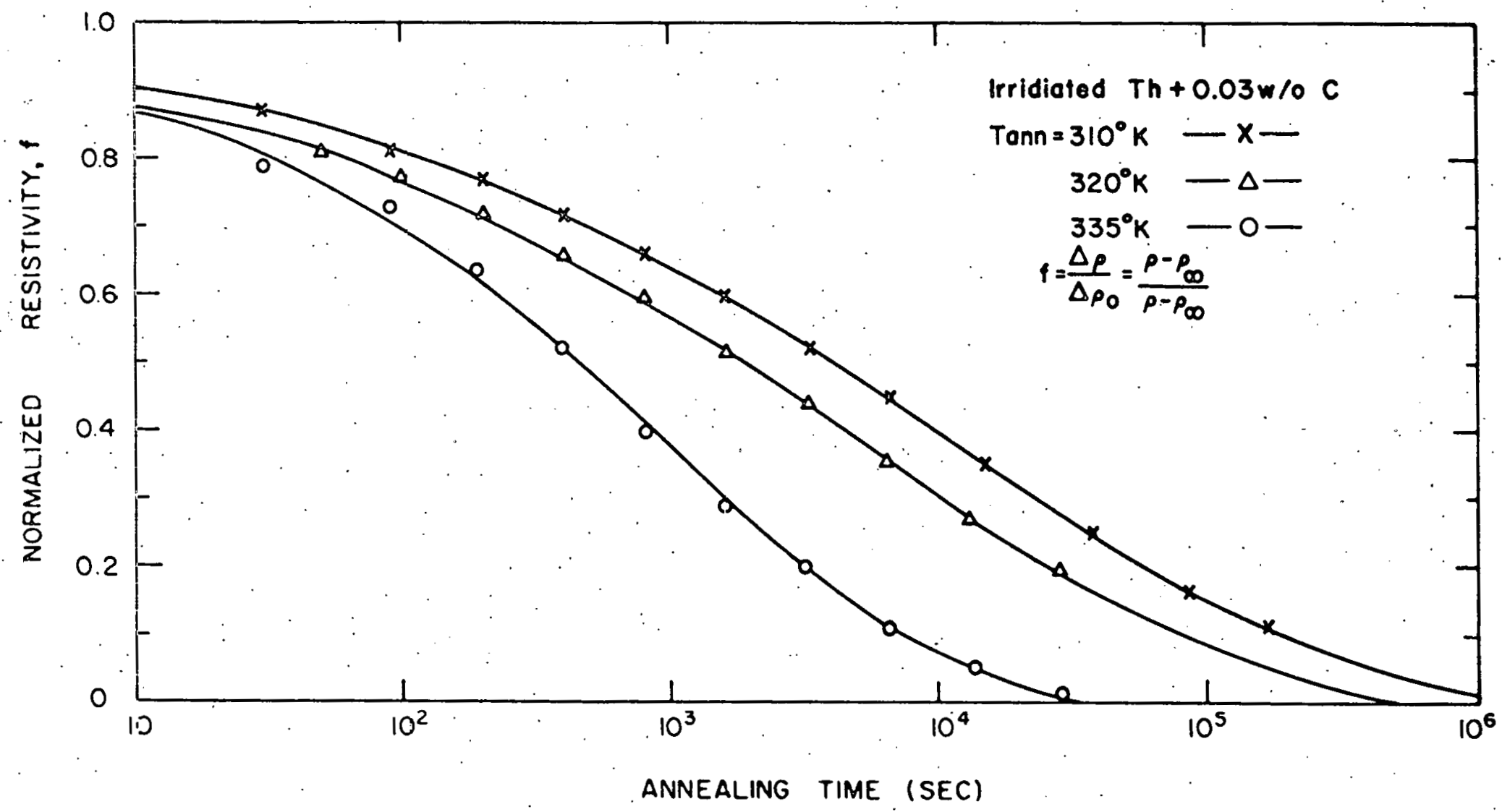

Figure 25. Isothermal annealing curves for irradiated Th-0.03 w/o C alloy specimens at different temperatures. 


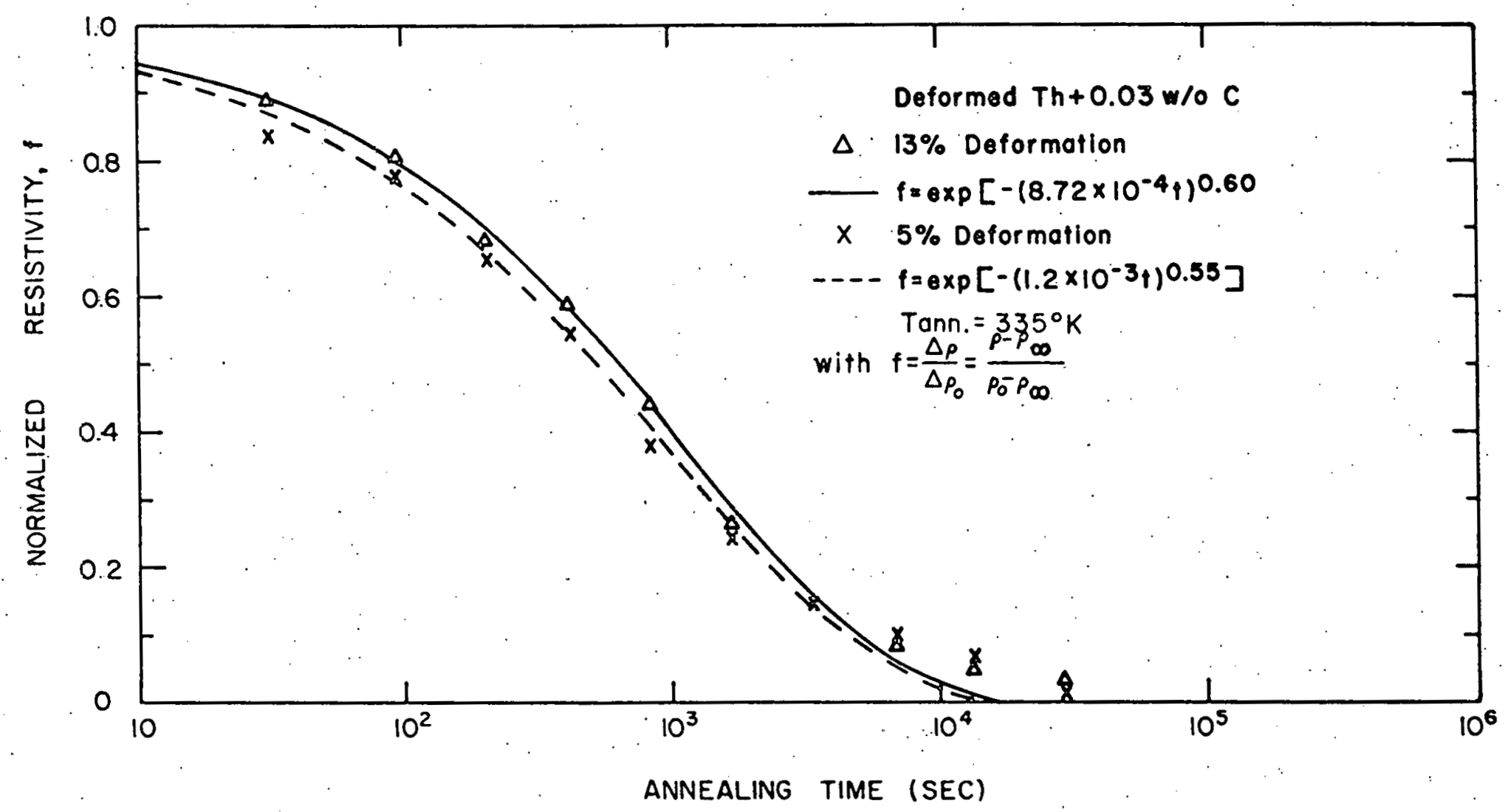

Figure 26. Isothermal annealing curves for cold-worked Th-C alloy specimens at $335^{\circ} \mathrm{K}$. 


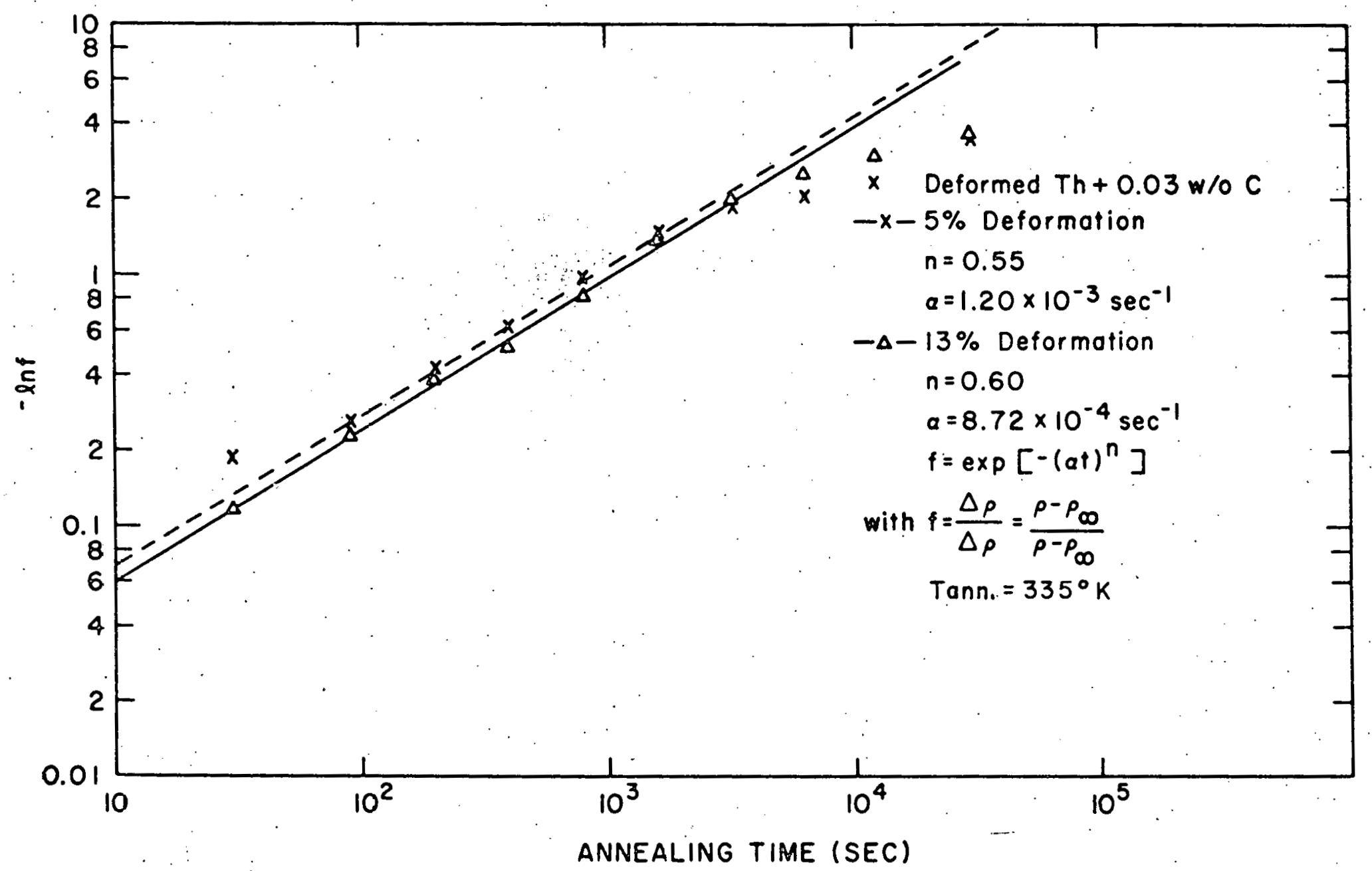

Flgure 27. Log-log plots of in $1 / f$ versus annealing time for cold-worked Th-C alloy specimens annealed at $335^{\circ} \mathrm{K}$. 


\section{DISCUSSION}

\section{Nature and Extent of Radiation Effect on the Resistivity of Thorium at $80^{\circ} \mathrm{K}$}

The excess resistivities, $\Delta \rho_{0}$; induced in thorium specimens by cold work or irradiation at $80^{\circ} \mathrm{K}$ are compared in Table 4. For the same fluence, the $\Delta \rho_{0}$ value is seen to Increase with increasing carbon content. This carbon effect is similar to that reported on neutron-irradiated specimens of the Al-Ge $(0.02-0.5$ at \%) alloys by Kontolen et al. (70). The dependence of $\Delta \rho_{0}$ - on carbon content is also detected in cold worked specimens. To interpret the carbon

Table 4. Comparison of excess resistivity values for thorium specimens after deformation and irradiation at $80^{\circ} \mathrm{K}$

\begin{tabular}{|c|c|c|c|c|}
\hline & \multicolumn{2}{|c|}{ Cold work } & \multicolumn{2}{|c|}{ Neutron irradiation } \\
\hline & $\Delta \rho_{Q}(\mu \Omega-c m)$ & Deformation & $\Delta \rho_{0} \quad(\mu \Omega-c m)$ & Fluence $\left(\mathrm{n} / \mathrm{cm}^{2}\right)$ \\
\hline$T-59$ & 0.47 & $17 \%$ & 1.10 & $\begin{array}{l}1.3 \times 10^{18} \\
(E>0.1 \mathrm{MeV})\end{array}$ \\
\hline Tc512 & 1.30 & $17 \%$ & 1.38 & $\begin{array}{ll}1.3 & \times 10^{18} \\
(\mathrm{E}>0.1 \mathrm{MeV})\end{array}$ \\
\hline $\operatorname{scsi2}$ & 1.48 & $21 \%$ & . & \\
\hline Tc.52a & 1.60 & $17 \%$ & & \\
\hline
\end{tabular}


effect on $\Delta \rho_{0}$, let us first refer to the work by Schmidt (62), who examined the resistivity recovery between $4.2^{\circ}$ and $80^{\circ} \mathrm{K}$ from radiation damage by internal alpha decay in thorium at $4.2^{\circ} \mathrm{K}$. He has concluded that migration of free interstitials is responsible for stage $-I_{E}$ at $35^{\circ} \mathrm{K}$ and that stage II.has two substages, $I I_{A}$ and $I I_{B}$, center1ng around $55^{\circ}$ and $73^{\circ} \mathrm{K}$. Following his conclusions, we assume that free interstitials would move very rapidly at $80^{\circ} \mathrm{K}$ : As described by Horak and Blewitt (71), irradiation with fast neutrons at $4.2^{\circ} \mathrm{K}$ will primarliy generate damage zones composed of vacancies, interstitials, and their clusters. At $80^{\circ} \mathrm{K}$, the interstitials induced inside the zones will either recombine with vacancies, conglomerate into clusters of variable sizes, or be trapped by impurities. After the irradiation at $80^{\circ} \mathrm{K}$, relatively few free interstitials can survive." The radiation-induced resistivity increment is then composed of contributions caused by vacancies, trapped interstitials, and clusters of both interstitials and vacancles.

It has been suggested (72) that traps or sinks for interstitials (and vacancies) may be termed unsaturable, saturable, and nucleational. This classification of traps is based on whether or not the capture radius of the trap would vary with defects already trapped. For unsaturable traps (dislocation, grain boundary, etc.), the capture 
radius is independent of the number of interstitials captured, whereas for saturable traps (vacancies and thelr clusters) the capture radius decreases with increasing number of "trapped" interstitials. The capture radius of nucleational traps (both homogeneous and heterogeneous nucle1), on the other hand, Increases with increasing number of trapped interstitials. In this classification, if impurity atoms act as nucleational traps for interstitials, the "concentration" of trapping sites (concentration of impurity atoms times capture volume of that impurity atom), as suggested by Wollenberger (72), would increase with increasing 1mpurity content. On the other hand, under the same fluence of Irradiation, the "concentration" of recombination sites (vacancy concentration times capture volume of vacancles) would have a constant value. If all specimens had the same thermal history before irradiation, the "concentration" of unsaturable sink sites (concentration of traps times capture volume per trap) in all specimens should also have a constant value. Hence, the probability that the migrating interstitials would recombine would be Increased with increasing purity or decreasing impurity content. This reasoning has been shown mathematically and experimentally by Dworschak et al. (73) for electronirradlated copper. The present observation that for a given neutron fluence, the excess resistivity values for the 
Th-0.03 w/o $C$ alloy specimens are higher than those for pure Th is what should be expected according to this trapping mechanism.

Peterson and Skaggs (63) observed that flow stress of thorlum increased with increasing carbon content and the increase is much greater when deformation is performed at lower temperatures. They assumed that this strengthening effect is due to a strong Interaction between moving dislocations and carbon atoms. In their interpretation, carbon atoms were assumed to act as strong obstacles: to moving dișlocations. Using a bond-energy model, they proposed that the lattice strain of a dislocation near a carbon atom in solution would be such as to change the length and orientation of the thorium-carbon bonds and therefore the bond energy. This change of energy implies in a strong dislocation-carbon atom interaction. For stronger interactions, the yield stress is increased and the dislocation bows to a smalier radius of curvature. After the dislocation passes through the carbon atoms, small dislocation loops would be generated around the carbon atoms. These loops can then interact with other dislocations and produce point defects by Friedel's model (41). Hence, it is possible that both the concentrations of the generated point defects and in dislocation density increase with increasing carbon content under the 
same amount of deformation. The increase in excess resistivities of the Th-C alloys shown in Table 4 may serve to justify this reasoning.

\section{Interpretation of Stage II Recovery above $80^{\circ} \mathrm{K}$}

Dworshak et al. (74) have recently investigated the interaction of migrating interstitiais with substitutional impurities in dilute copper alloys irradiated with electrons between $50^{\circ}$ and $170^{\circ} \mathrm{K}$. By applying the pertinent diffusion theory of self-interstitials, the capture radii of various impurities for migrating interstitials and the resistivity induced by trapped interstitials have been determined. The deduced capture radil of all impurities ( $\mathrm{Au}, \mathrm{Ge}, \mathrm{Ni}$, $\mathrm{Pd}, \mathrm{Sb}$, and $\mathrm{Zn}$ ) studied except Be were found to decrease with increasing irradiation temperature and become zero at about $110^{\circ} \mathrm{K}$. From the colncidence of this temperature with the stage II temperature range for copper, they concluded that stage II recovery for copper is caused by the detrapping of interstitials.

Although the charge in capture radius of carbon atoms for migrating interstitials in thorium with temperature is st1ll unknown, the enhancement of stage II $_{C}$ recovery observed in the irradiated Th-0.02 w/O C specimens suggests that detrapping of interstitials from impurities might be 
the dominant mechanism for the stage $I I_{C}$ recovery. The detrapped Interstitials may then migrate ( 1 ) to form clusters, (2) to recombine with vacancies, and (3) to other stronger traps.

In deformed thorium the number of disiocations present is so large that they act as the primary sinks. Generally, for a dislocation network the average number of fumps of a point defect to reach a dislocation in random walk is of the order (41),

$$
\mathrm{n}_{j} \approx \frac{1}{1 \mathrm{a}^{2}} \approx \frac{10^{15}\left(\mathrm{~cm}^{-2}\right)}{!}
$$

where $\Lambda$ is the dislocation density and a the interatomic distance. (The number of jumps is smaller when the diffusion is assisted by the dislocation stress flelds and larger when the dislocation distribution is nonuniform.) Another consequence of high density dislocations is the diminution of the influence of impurities on annealing-out of point defects.

It has been described previously that concentrations of point defects and dislocations in thorlum would be increased with increasing carbon content or deformation. The increases in point defects and in dislocations could be proportional to each other. The independence of the percentage recovery of both stage II (above $80^{\circ} \mathrm{K}$ ) and stage III for deformed thorium from carbon content and the amount of 
deformation may possibly verify this assumption. The stage II recovery above $80^{\circ} \mathrm{K}$ can be divided into two regions. The first region is from $80^{\circ}$ to $150^{\circ} \mathrm{K}$ and the second region Is from $150^{\circ}$ to $240^{\circ} \mathrm{K}$. Because of the increase of percentage recovery with increasing carbon content in the first region of stage II in Figure 6 , it is possible that detrapping of interstitials from carbon atoms may occur in this temperature range. Therefore, the stage II recovery peak at $200^{\circ} \mathrm{K}$ (the second region of stage II) may be only contributed by detrapping of interstitials from other impurities (possibly $O, N$, or other substitutional impurities). This interpretation is consistent with the fact that there are more than 200 wt. ppm of other impurities than carbon. in the thorium specimens. It is reasonable only if the interstitial-O and $-\mathrm{N}$ atom complexes have larger binding energies than that of the interstitial-C atom complex. Without knowing the binding energies of various interstitial-impurity complexes, however, this interpretation is only tentative.

\section{Activation Energy and Interpretation of Stage III Recovery}

The rat10-of-slope method was used to determine the activation energies for migration of defects in stage $\mathrm{II}_{\mathrm{C}}$ and III in both irradiated and cold worked specimens. This 
method has the important advantage that the requirement of identical defect configurations at two temperatures is fulfilied automatically. All other methods necessitate the use of two or more specimens, thus having the disadvantage that all specimens must have identical inftial defect state. In many cases, because of background annealing, the resistivity values at which a given annealing stage begins and ends cannot be determined precisely (especlally the limiting value $\Delta \rho_{\infty}$ of the 1sothermal annealing). Also, the total amount of recovery in stage III often varies from specimen to specimen even for ldentical irradiation conditions, especially at low defect densities. Therefore, despite the high accuracy claimed elsewhere (26), the somewhat different values deduced for $E_{I I I}$ by using the MB and the cross-cut methods are not particularly surprising. Likewise, the graphical method used for the determination of the exponent $n$ in the empirical kinetic equation has problems on rellability and reproducibility. All experimental results Indicate that migration of the same type of point defects is responsible for recovery in the latter stage in both coldworked and irradiated specimens. This conclusion is based on the following observations: (1) The same activation energles were obtalned using the ratio-of-slope method. (2) The stage III recovery from both cold-worked and irradiation falls in the same temperature range $\left(250-400^{\circ} \mathrm{K}\right)$, 
and (3) the recovery curves have the same structure featuring one main peak at $315-330^{\circ} \mathrm{K}$.

The stage III recovery cannot be related to the migration of extrinsic impurity atoms (such as carbon atoms) because of the great enhancement of this stage observed in Irradiated pure thorlum instead of Th-C alloy specimens. Furthermore, the migration energy for diffusion of carbon atoms in $\alpha-T h$ has been estimated to be $1.62 \mathrm{eV}$ (75), which is too high in comparison with the deduced values of activation energy for stage III. Since migration and detrapping of interstitials have been assigned to stages I and II, then vacancy (mono- or di-vacancy) migration might be a logical cholce for stage III recovery.

- Unfortunately, the experimental value for the activation energy of single vacancy migration in thorium is still not available: The activation energy for self-diffusion, $E_{d_{*}}$, (equal to the formation and migration energies of single vacancies) of the fcc $\alpha-\mathrm{Th}$, is reported at $77.6 \mathrm{kcal} / \mathrm{mole}$ $(3.3 \mathrm{eV} /$ atom) (75). A rule of thumb for the estimation of the formation energy of a vacancy, $E_{V}^{F}$, in the fcc metals is above $1 \mathrm{eV}$ per $1000^{\circ} \mathrm{C}$ of the melting point. This estimation is generally valid to within 10\%. Based on this rule, $\mathrm{E}_{\mathrm{V}}^{F}=1.75 \mathrm{eV}$ for Th. Taking the difference between $\mathrm{E}_{\mathrm{d}^{*}}$ and $E_{V}^{F}$ gives $E_{V}^{M}=1.55$ eV for the migration energy of single vacancies in $\alpha-T h$. 
Flynn (76) has derived a theoretical expression for diffusion jump in a monatomic crystal:

$$
v=\left(\frac{3}{5}\right)^{1 / 2} \cdot v_{D} \exp \left[-C \Omega \delta^{2} / k T\right]
$$

where $\nu_{D}$ is the Debye frequency, $\Omega$ the atomic volume, and $C$ an average elastic constant for migration calculated from

$$
\frac{15}{2 C}=\frac{3}{C_{11}}+\frac{1}{C_{11} C_{12}}+\frac{1}{C_{44}}
$$

where $C_{11}, C_{12}$, and $C_{44}$ are the three 1ndependent elastic constants for cubic metals. The quantity $\phi=c \Omega \delta^{2}$ plays the part of a Gibbs function for migration. For thorium, the following data were suggested: $C=6.02 \times 10^{10} \mathrm{~N} / \mathrm{m}^{2}$, $\Omega=3.29 \times 10^{-29} \mathrm{~m}^{3} /$ atom, $\nu_{D}=10^{14} \mathrm{sec}^{-1}$, and $\delta^{2}=0.104$. The theoretical estimation of migration energy", therefore, can be obtained by combining eq. (12) with the following diffusion expression for fcc crystals,

$$
v=\frac{6}{a^{2}} \cdot D_{0} \exp \left[-E_{V}^{M} / k T\right]
$$

Using $a=5 \times 10^{-8} \mathrm{~cm}, D_{0}=2100 \mathrm{~cm}^{2} / \mathrm{sec}$ for thorium, and $T=400^{\circ} \mathrm{K}$, the theoretical value for $\mathrm{E}_{\mathrm{V}}^{\mathrm{M}}$ is estimated to be $1.65 \mathrm{eV}$. This value seems to be reasonable when compared with the value obtained from considerations involving selfdiffusion. Both calculated values of $E_{V}^{M}$, however, are about 
$0.5 \mathrm{eV}$ greater than the activation energy obtalned for the stage III recovery. If the latter activation energy is an Indication of the defects involved in the mechanism dominating this recovery stage, the deduced value of $E_{I I I} \sim 1.15 \mathrm{eV}$ would imply that single vacancy migration is not responsible for the stage III recovery in Th.

Because point defects induced by deformation at.low temperatures are produced in rows, according to most models, many of the vacancies thus generated might lead to the formation of divacancies. For fast neutron irradiation, only relatively few defects (vacancies and interstitials) are produced in isolated forms, others in the displacement cascades are more or less correlated or clustered. According to Schiling et al. (22), because of the greater mobility of free interstitials than vacancles at $80^{\circ} \mathrm{K}$, isolated vacancies have a great chance. to be annihilated by moving interstitials. On the other hand, the arrangement of point defects in the defect zones tend to bring vacancies together in di-, tri-, and multi-vacancy forms. Also, the very presence of vacancies in the interior of defect zones would enhance their changes of survival from recombinations during Irradiation and thermal annealing prior to stage III. Therefore, for fast neutron irradiated thorlum, presence of rather high concentration of vacancy complexes (divacancy, trivacancy, ...) below stage III is conceivable. 
Although the migration energy of divacancy, $E_{2 V}^{M}$, has not been evaluated experimentally for thorlum, Table 5 shows the experimental values of migration energies for both single vacancies and divacancies in typlcal fcc metals (77). The estimated migration energy for single vacancies and the observed stage III activation energy for thorium are also listed in this table. An examination of these values and the ratios of $E_{2 V}^{M} / E_{V}^{M}$ reveals that while $E_{V}^{M}$ and $E_{2 V}^{M}$ values vary widely by a factor of more than two, the $\mathrm{E}_{2 \mathrm{~V}}^{\mathrm{M}} / \mathrm{E}_{\mathrm{V}}^{\mathrm{M}}$ ratios fall in a closè range 0.60 to 0.80 . More importantly, the identification of the deduced activation energy of

Table 5. Migration energies of single vacancy and divacancy for f.c. metals.

\begin{tabular}{|c|c|c|c|c|c|c|c|}
\hline & A I & $\mathrm{Ag}$ & $P t$ & $\mathrm{Cu}$. & $\mathrm{N} 1$ & $\mathrm{Au}$ & Th \\
\hline$E_{V}^{M}(e V)$ & 0.62 & 0.83 & 1.38 & 0.85 & 1.40 & 0.90 & $(1.65)^{a}$ \\
\hline$E_{2 V}^{M}(e V)$ & 0.42 & 0.57 & 1.10 & 0.71 & 0.85 & 0.71 & $(1.15)^{b}$ \\
\hline $\mathrm{E}_{2 \mathrm{~V}}^{\mathrm{M}} / \mathrm{E}_{\mathrm{V}}^{\mathrm{M}}$ & 0.68 & 0.69 & 0.80 & 0.84 & 0.61 & 0.79 & 0.70 \\
\hline & & & . & 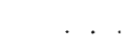 & & & \\
\hline
\end{tabular}


$1.15 \mathrm{eV}$ with the mlgration energy of divacancles in Th ylelds a $E_{2 V}^{M} / E_{V}^{M}$ ratio of 0.70 , which lies in the middle of the range. Th1s may in part support the tentative interpretation that the stage III recovery in Th is due mainly to the migration of divacancies.

As has been mentioned before, the activation energy $E_{\text {III }}$ was found to decrease slightly with increasing carbon content. Several possibilities may be clted for the carbon effect. One was proposed by Lazarus (7.8) that the impurity atoms tend to form complexes with vacancles, especially when the impurity atoms are multivalent. According to the latter author, the complexes can diffuse more rapidy than single vacancies. Should the Lazarus mechanism be valid, the migration energy would have been lowered as the total impurity concentration increased. Applying this model to thorium, an enhancement of the stage III recovery would be expected in the Th-C alloys. This expectation has not been observed, however. Therefore, the impurity-vacancy complex model must be ruled out.

Another possiblity is that proposed by Koehler (77), who invoked the model of divacancy migration in an attempt to explain results obtained from quenching experiments conducted on gold. Koehler's model involves the following assumptions: (1) changing the state of purity would change the sink density $\mathrm{C}_{S}$, (2) $\mathrm{C}_{\mathrm{S}}$ would depend on yield stress at 
some critical temperature, and (3) the yleld stress would Increase as the impurity concentration increases. The increase in excess resistivity with increasing carbon content in thorium has been discussed previously and carbon atoms were proposed as nucleational traps for defects. Therefore, changing the carbon content of thorium specimens would change the sink density. It was also discussed that in cold-worked thorlum specimens, the presence of carbon atoms increases not only the concentration of point defects; but also that of dislocations, which are the primary sinks for defects. Peterson and Skaggs (63) have observed that increasing carbion content in thorium tends to increase the yield stress. They also observed an increase in yleld stress with decreasing temperature with an upper critical temperature at about $423^{\circ} \mathrm{K}$. Hence, the assumptions for Koehler's divacancy-migration model are quite feasible for thorium. This may also support the tentative interpretation of the stage III recovery based on the migration of divacancies.

In neutron irradiated thorium a fraction of the excess resistivity remalned after completion of stage III, Indicating the retention of radiation-induced defects after stage III. The fraction of remaining damage increases as the carbon content is increased. This might be due to the formation of defect.clusters at carbon atoms which act as 
nucleational traps. It is also possible that divacancles might be trapped by carbon atoms during the migration as observed by Sorensen (79) in his neutron-irradiated nickel. In cold-worked specimens, the carbon effect on defect retention is not observed. One good reason for this is that the presence of the high concentration of dislocations, being effective sinks for defects, may mask the influence of carbon atoms. The influence of dislocations on the annealing-out of point defects has been described by van den Beukel (4I). The latter worker also assumed that 55\% of the total increase in resistivity in $\mathrm{Cu}$ during low temperature deformation is due to point defects. If a similar contribution from point. defects to $\Delta \rho_{0}$ is envisaged for thorium specimens, then, at the end of stage III, more than $20 \%$ of the induced resistivity contributed by point defects would still remain. The remaining point defects may be mainly large clusters which eventually collapse to form dislocation loops or to dissociate at higher annealing temperature.

From the foregoing discussion, it may be concluded that stage III recovery for both neutron-irradiated and coldworked thorium is possibly due to the migration of divacancies.

Finaliy, data obtained from the stage III isothermal annealing do not fit the simple rate equation. Rather, they fit the Johnson-Mehl emplrical equation. Although the 
$\alpha\left(\sec ^{-1}\right)$ value in the Avrami equation is not a true rate constant, its value varies sensitively with the conditions of specimen and annealing temperature. For Instance, the observed increase of $\alpha$ value with increasing annealing temperature for Irradiated thorium shows the increase of the initial annealing rate. It was also observed that the $\alpha$ value deduced from annealing at $310^{\circ}$ and $320^{\circ} \mathrm{K}$ is decreased by the presence of carbon atoms in the lattice. The latter result implies that at these temperatures the inftial annealing rates were suppressed by carbon atoms. The decrease in a value due to impurity was also found in neutron irradiated $\mathrm{V}$ and Mo (32). The suppression of the inftial annealing rate, however, disappeared. when the annealing temperature was increased to $335^{\circ} \mathrm{K}$. This change of $\alpha$ with carbon content may be due to the difference in sink distribution at the beginning of stage III recovery. The exponent, $n$, value is generally related to the nature and/or density of sinks. The difference in the $n$ value between pure Th and the Th-C alloy is not obvious. However, for isothermal anneal at $335^{\circ} \mathrm{K}$, the $\mathrm{n}$ values for irradiated and cold-worked specimens are 0.43 and $0.5 \sim 0.6$, respectively. In fast neutronirradiated specimences the main sinks for divacancies might be the interstitial clusters or other defects, whereas in cold-worked specimens they might be dislocations. 


\section{SUMMARY}

The damage induced in thorium by both fast neutron irradiation and cold work at liquid nitrogen temperature is increased with increasing carbon content. The activation energy of stage II annealing for cold-worked thorium is $0.61 \pm 0.07 \mathrm{eV}$, and this value decreases as the carbon content increases. The migration of detrapped interstitials from impurtties is proposed to be the dominant mechanism in stage $I I_{C}$ recovery. For irradiated specimens detrapped interstitials migrate to form clusters or to recombine with vacancies, whereas for cold-worked specimens detrapped interstitials migrate to dislocations.

The migration energy of single vacancles in thorium is calculated to be $1.65 \mathrm{eV}$. The activation energy of stage III annealing is determined to be $1.16 \mathrm{eV} \pm 0.08 \mathrm{eV}$ for coldworked thorium and $1.14 \mathrm{eV} \pm 0.04 \mathrm{eV}$ for neutron-irradiated thorium by the ratio-of-slope method. The activation energy Is deduced to be $0.98 \mathrm{eV}$ for irradiated specimens by the $\mathrm{MB}$ method. The inconsistency may be due to the inherent experimental error of the methods, especially the MB method.

Because the stage. III annealing for both coldworked and irrailiated thorium has the same activation energy, the same temperature range $\left(250-400^{\circ} \mathrm{K}\right)$ and the same structure with one peak at $315-330^{\circ} \mathrm{K}$, we conclude 
that migration of the same type of point defects may be the dominant mechanism. Divacancy migration is chosen as the possibie mechanism in stage III recovery for the following reasons: (I) the observed activation energy seems to represent the migration energy of divacancy in view of the $E_{2 V}^{M} / E_{V}^{M}$ ratio for various fcc metals. (2) A divacancymigration model can explain the observation that the activation energy decreases with increasing carbon content. (3) Defect retention (more than $20 \%$ and $27-35 \%$ of the initial damage production for cold-worked and neutronirradiated thorium, respectively) above stage III is observed.

The stage III anneals do not fit the simple chemical rate equation, but they can be described by the Avrami empirical equation. The difference in the exponential $n$ value may be due to the difference in sinks; for irradiated specimens divacancies may mainly migrate to interstitial clusters or other defects, whereas for cold-worked specimens dislocations might be the maln sinks for divacancles.

It is recommended that in order to get a comprehensive knowledge about the recovery behavior of thorium, quench experiments are needed. Experimental values for migration energy of single vacancy and divacancy in thorium should be established. Our current knowledge about defect-impurity interactions is incomplete to obtain a better explanation 
of the effect of carbon atoms on the thorium recovery behavior. Therefore, more work in this fleld is needed. Furthermore, study of stage IV recovery may also be found fruitful in confirming the stage III recovery mechanism proposed here. 


\section{BIBLIOGRAPHY}

1. J.W. Corbett, Electron Radiation Damage in Semiconductors and Metals, Academic Press, New York, 1966.

2. A. C. Damask and G. J. Dienes, Point Defects in Metals, Gordon and Breach, New York, 1963.

3. For a general discussion of electrical resistivity see: H. M. Rosenberg, Low Temperature Solid State Physics; Oxford University Press, New York, 1963, pp. 74-100; and $C$. Kittel, Introduction to Solid State Physics, 4 th ed., John Wiley and Sons, New York, 1971, pp..257262 .

4. D. K. Holmes, "Radiation Damage in Non-Fissionable Metals," in The Interaction of Radiation with Solids, R. Strumane, J. Nihoul, R. Gevers, and S. Amelinchx, Eds.; North-Holland Publishing Co., Amsterdam, $1964^{\circ}$

5. H. G. Cooper, J: S. Koehler, and J. M. Marx, Phys. Rev., 97, 599 (1.955).

6. J.W. Corbett, Electron Radiation Damage in Semiconductors and Metals, Academic Press, New York, 1966.

7. M. S. Wechsler, "Radiation Effects, Diffusion and BodyCentered Cubic Metals," In Diffusion in Body-Centered Cubic Metals, American Society. for Metals, Metals Park, Ohio, 1965.

8. J.W. Corbett, R. B. Smith, and R: M. Walker, Phys. Rev., I14, I452 (1959).

9. J. W. Corbett, R. B. Smith, and R. M. Walker, Phys. Rev., 114, 1460 (1959).

10. R. M. Scanian, D. L. Styris, and D. N. Seidman, Ph11. Mag., 23, 1439 (1971).

11. R. M. Scanlan, D. L. Styris, and D'. N. Seidman, Ph11. Mag., 23, 1459 (1971).

i2. N. Kontoleon, K. Papathanassopoulos, K. Chountas, and

P. Andronikos, J. Nucl. Met., 54, 265 (1974). 
13. A. Sosin in Lattice Defects and Their Interactions,

R. R. Hasigut1, Ed., Gordon and Breach, New York, 1967 .

14. J. L. Oddou, C. Minier-Cassayre, and P. Moser, Phys. Stat. Sol., 17, 793 (1966).

15. C. L. Snead and P. E. Shearin, Phys. Rev., 140, A1781 (1965).

16. P. B. Peters and P. E. Shearin, Phys. Rev., 174, 691 (1968).

17. A. Sosin and L. H. Rachal, Phys. Rev., 130, 2238 (1963).

18. K. R. Garr and A. Sosin, Phys. Rev., 162;699 (1967).

19. D. G. Martin, Phil. Mag., 6, 803 (1961).

20. J. P. Riviere and J. Grilhe, Scripta Met., $\underline{8}, 889$ (1974).

21. W. Schilling, P. Ehrhart, and K. Sonnenberg, "Interpretation of Defect Reactions in Irradiated. Metals by the One Interstitial Model," presented in the International Conference on Fundamental Aspects of Radiation Damage in Metals, Gatlingburg, Tennessee, 1975 .

22. W. Schilling, G. Burger, K. Isebeck, and H. Wenzl, "Annealing Stages in the Electrical Resistivity of Irradiated FCC Metals," in Vacancies and Interstitials in Metals, A. Seeger, D. Schumacher, W. Schiling, and J. Diehl, Eds., Wlley Interscience, New York, 1970 .

23. Y. N. Lwin, M. Doyama, and J. S. Koehler, Phys. Rev., 165, 787 (1968).

24. C. L. Budin, P. Lucasson, and A. Lucasson, J. Phys., 26; 9 (1965).

25. C. Lee and J. S. Koehler, Phys. Rev., 176, 813 (1968).

26. W. Bauer and A. Sosin, Phys. Rev., 136, A474 (1964).

27. G. Duesing and W. Schilling, Radiation Effects, I, 65 (1969). 
28. J. A. Horak and. T. H. Blew1tt, Report ANL-MS-1503, Argonne, Ill.; 1974.

29. J. Nihoul, "Vacancies and Interstitials in Body-Centered Cubic Transition Metals," in Interstitials and Vacancies In Metals, A. Seeger, D. Schumacher, W. Schilling, and J. Diehl, Eds., Wiley Interscience, New York, 1970.

30. J. T. E. Nihoul, "Radiation Damage and Recovery in Metals," in Radiation Damage in Reactor Materials, Internationa I Atomic Energy Authority, Vienna, 1969 .

3i. J. T. Stanley, J. M. Wllliams, W. E. Brundage, and M. S. Wechsler, Acta Met., 20, 191 (1972).

32. J. F. McIlwain, Ph.D. Thesis, Iowa State University, Ames., Iowa, 1973.

33. C. Frois and 0. Dimitrov, Acad. Sci., Paris, 264C, 1923 (1967).

34. C. Dimitrov-Frois and 0. Dimitrov, in Proc. of International Conference on Vacancies and Interstitials in Metals, Vol. 1, 290, Jülich, Germany, 1968.

35. C. Dimitrov-Frois and O. Dimitrov, Mem. Sci. Rev. Met., 65, 425 (1968).

36. C. Frois and 0. Dimitrov, Acad. Sci., Paris, 263, 1496 (1966).

37. C. Dimitrov, F. Moreau, and O. Dimitrov, J. Phys. F, 盾, $385(1975)$.

38. K. R. Garp and A. Sosin, Phys. Rev., 162, 681 (1967).

39. J. Molenaar, W. H. Aarts, Nature (London), 166, 690 (1950).

40. R. W. Balluff1, J.S. Koehler, and R. O. Simmons, "Present. Knowledge about Point Defects in Deformed FCC Metals," in Recovery and Recrystallization of Metals, L. Himmel, Ed., Intersicience, New York, 1962 .

41. A. van den Beukel, "Point Defects in Cold Worked FCC Metals," in Vacancies and Interstitials of Metals, A. Seeger, D. Schumacher, W. Schilling, and J. Diehl, Eds., Wiley Interscience, New York, 1970. 
42. G. R. Piercy, Phil. Mag., 5, 201 (1960).

43. C. Frois, Acta Met.; 14, 1325 (1966).

44. J.J. Jackson, "Point Defects in Quenched Platinum," in Lattice Defects in Quenched Metais, R. M.J. Cotterill et al., Eds., Academic Press, New York, 1965.

45. A. van den Beukel, Acta Met., II, 97 (1963).

46. P. Merkien and 0. Dimitrov, Mem. Sci., 63, 871 (1966).

47. 0. Buck, Phys. Stat. Sol., 2, 535 (1962).

48. J. W. Corbett, Electron Irradiation Damage in Semiconductors and Metals, Academic Press, New $\overline{\text { York, }}$ 1966.

49. W. Schule, A. Seeger, D. Schumacher, and K. King, Phys. Stat. Sol., 2, 1199 (1962).

50. J. W. Henderson and J. S. Koehler, Phys. Rev., 104, 626 (1956).

51. A. S. Nowick, Acta Met., 3, 312 (1955).

52. D. Schumacher and A. Seeger, Phys. Letters, .7, 186. (1963).

53. D. Schumacher, Scripta Met., 2, 209 (1968).

54. F. Pieragostini, C. Ceresara, and T. Federighi, Acta Met., 14, 450 (1966).

55. A. Seeger and H. Mehrer, "Analysis of Self-diffusion and Equilibrium Measurements," in Vacancies and Interstitials in Metals, A. Seeger et al., Eds., Wiley Interscience, New York, 1970.

56. W. Baner, A. Seeger, and A. Sos1n, Phys. Letters, 24A, $195(1967)$.

57. H. I. Dowson, Acta Met:, 13, 453 (1965).

58. S. Ceresara, Phil. Mag., 17, 1299 (1968).

59. S. Ceresara and T. Federighi, Ph11. Mag., 18, 301 (1968). 
60. J.A. Brinkman and W. S. Gilbert, Effects of Fission Fragments on Radiation Damaged Materials, USAEC Report NAA-SR-262, 1953 .

6I. F. E. Bowman, A. Andrew, R. R. Eggleston,

F. L. Fillmore, and C. J. Meechan, Cyclotron Irradiation Damage of Thorium, Stainless, and Zirconium, USAEC Report NAA-SR-287, 1954.

62. D. Schmidt, Ph.D. Thesis, University of California, Berkeley, California, 1971.

63. D. T. Peterson and R. L. Skaggs, Trans. TMS-AIME, 242, $922(1968)$.

64. D. T. Peterson and D. R. McLachlan, Met. Trans. A, 6A, 1359 (197.5).

65. R.P. Zerwekh and T. E. Scott, Trans, TMS-AIME, 239, 432 (1967).

66. J. Friedel in The Relation Between the Structure and Mechanical Properties of Metals, National Physical Laboratory Symposium 15 , Her Majesty's Stationery Office, London, 1963, p. 409.

67. W. J. Hurford, USAEC Report TID-5061, Oak Ridge, Tenn:, 1952.

68. 0. Dimitrov and C. Dimitrov-Frois in Proc. of International Conference on Vacancles and Interstitials in Metals, Vol. 1, 304, Jülich, Germany, 1968.

69. J. Burke, "The Kinetics of Phase. Transformations in Metals," Pergamon Press, Oxford, 1965.

70. N. Kontoleon, K. Papathanassopoulos, and K. Chountas, Phys. Letters, 53A, 5, 413 (1975).

71. J.A. Horak and T. H. Blewitt, J. Nucl. Mat., 49, $161(1973 / 74)$.

72. H. J. Wollenberger; "Production Rates of Frenkel Defects During. Low-Temperature Irradiation," in Interstitials and Vacancies in Metals, A. Seeger, D. Schumacher, W. Schiling, and J.DiehI, Eds., W1ley Interscience, New York, 1970 .

73. F. Dworschak, H. Schuster, H. Wollenberger, and J. Warm, Phys. Stat. Sol., 29, 75, 81 (1968). 
74. F. Dworshak, R. Lennartz, and H. Wollenberger, J. Phys. F: Metal Phys., 5, 400 (1975).

75. J. F. Smith, O. N. Carison, D. T. Peterson, and T. E. Scott, Thorium: Preparation and Properties, Iowa State University Press, Ames, Iowa, 1975.

76. C. P. Flynn, Phys. Rev., 171, 682 (1968).

77. J. Koehler, "Electrical Resistivity Measurements of Vacancy Annealing," in Vacancies and Interstitials in Metals, A. Seeger, D. Schumacher, W. Schilling, and J. Diehl, Eds., Wiley Interscience, New York, 1970.

78. D. Lazarus, "Diffusion in Metals," in Solid State Physics, Vol. 10, F. Seitz and D. Turnbul, Eds., Academic Press, New York, 1960, p. 71.

79. S.M. Sorensen; Jr., Ph.D. Thesis, Iowa State University, Ames, Iowa, 1976. 


\section{ACKNOWLEDGEMENTS}

I'would l1ke to sincerely thank my advisor, Dr. C. W. Chen, for h1s professional guidance and encouragement throughout the investigation. Much gratitude is due Dr. D. T. Peterson and Dr. P. Chiotti for their advice and for providing the materials. Also, I am indebted to Dr. M. S. Wechsler for his interest and helpful discussion. The experimental work would not have been carried out without the help of Wayne Buttry, Les Reed, Bruce IInk, and the other members of the ALRR Division. Their assistance and services are gratefully acknowledged. The experlence and expertise provided by Ms. Sue Musselman in typing this manuscript is greatly appreclated.

Special thanks is due the Nuclear Energy Research Institute of the Republic of China in Taiwan for providing the on leave and financial support.

Finally, I would like to dedicate this work to my wife, Helen, for her encouragement, underotanding and patience which endured throughout my stay at this University. 